\title{
DESENVOLVIMENTO DE SOFTWARES PARA APLICAÇÃO EM MEDICINA NUCLEAR: CÁLCULO DA BLINDAGEM PET/CT E OTIMIZAÇÃO DE DOSE PARA RADIOFÁRMACO
} EM PET/CT.

Dissertação apresentado ao Programa de Pós-Graduação em Ciências e Tecnologias em Saúde.

Área de concentração: Mecanismos Básicos e Tecnologias em Saúde.

Linha de investigação: Tecnologia Aplicada à Saúde.

Temática: Desenvolvimento de software para aplicação em Medicina Nuclear.

Orientador: Prof. Dr. Araken dos S. Werneck Rodrigues

Brasília

Junho de 2016 


\begin{tabular}{|c|c|}
\hline \multirow[t]{3}{*}{ NP372d } & $\begin{array}{l}\text { Nascimento, Pedro Augusto } \\
\quad \text { DESENVOLVIMENTO DE SOFTWARES PARA APLICAÇÃO } \\
\text { EM MEDICINA NUCLEAR: CÁLCULO DA BLINDAGEM PET/CT E } \\
\text { OTIMIZAÇÃO DE DOSE PARA RADIOFÁRMACO EM PET/CT. / } \\
\text { Pedro Augusto Nascimento; orientador Araken Santos Werneck } \\
\text { Rodrigues. -- Brasília, 2016. } 61 \text { p. }\end{array}$ \\
\hline & $\begin{array}{l}\text { Dissertação (Mestrado - Doutorado em Ciências e } \\
\text { Tecnologias em Saúde) -- Universidade de Brasília, } 2016 .\end{array}$ \\
\hline & $\begin{array}{l}\text { 1. Física Médica. 2. Medicina Nuclear. 3. Dose PET/CT. } 4 . \\
\text { Blindagem PET/CT. 5. Aplicativo. I. Santos Werneck Rodrigues, } \\
\text { Araken , orient. II. Título. }\end{array}$ \\
\hline
\end{tabular}


Universidade de Brasília

Faculdade de Ceilândia

Programa de Pós-Graduação em Ciências e Tecnologias em Saúde Mestrado em Ciências e Tecnologias em Saúde.

Mecanismos Básicos e Tecnologias em Saúde.

\section{DESENVOLVIMENTO DE SOFTWARES PARA APLICAÇÃO EM MEDICINA NUCLEAR: CÁLCULO DA BLINDAGEM PET/CT E OTIMIZAÇÃO DE DOSE PARA RADIOFÁRMACO} EM PET/CT.

BANCA EXAMINADORA

Prof. Dr. Araken dos S. Werneck Rodrigues (FCE - UnB) - Titular

Prof. Dr. Bernardo de Assunção Mello (IF - UnB) - Titular

Prof. Dr. Juliano Alexandre Chaker (FCE-UnB) - Titular

Prof. Dr. João Paulo Ataíde Martins (IESB) - Suplente 
Dedico esse trabalho aos meus pais e a Juliana, minha esposa. 


\section{AGRADECIMENTO}

Agradeço,

Primeiramente a Deus, pela existência e pelas oportunidades de aprender.

Aos meus pais, aos meus irmãos e aos meus parentes pelo apoio de todas as horas.

A minha amiga de todas as horas, minha esposa Juliana, por me doar seu tempo e atenção, pelo apoio constante, pelas inúmeras revisões e pelo amor.

Ao professor Araken dos S. Werneck Rodrigues, meu orientador, por me nortear na construção desse projeto.

Aos sinceros amigos que conquistei durante a Pós-graduação nesta Universidade.

Ao amigo de profissão de magistério na Secretaria de Educação do Distrito Federal.

Aos professores do Programa de Pós-Graduação em Ciências e Tecnologias em Saúde e aos profissionais da Universidade de Brasília pela atenção e o carinho.

À Universidade de Brasília, que me propiciou esses valiosos momentos de aprendizado. Também aos meus mestres e amigos da Universidade Católica de Brasília, onde me graduei.

A Secretaria de Estado e Educação do Distrito Federal pela oportunidade de estar afastado do trabalho para estudo, e haver possibilitado executar esse projeto em regime de dedicação integral.

A todos, sinceros agradecimentos hoje e sempre. Muito obrigado! 


\section{SUMÁRIO}

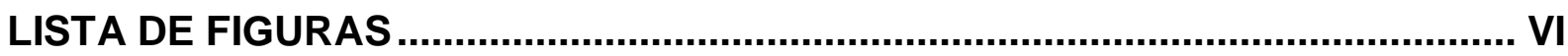

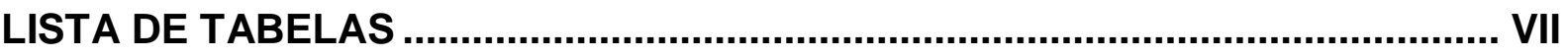

LISTA DE ANEXOS

LISTA DE SIGLAS E SÍMBOLOS ................................................................ IX

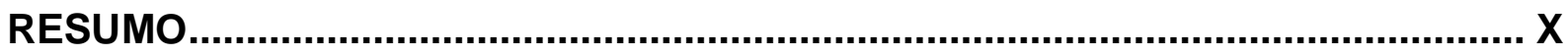

ABSTRACT

1 INTRODUÇÃO

1.1 RADIAÇÃO IONIZANTE E APLICAÇÕES MÉDICAS....................................13

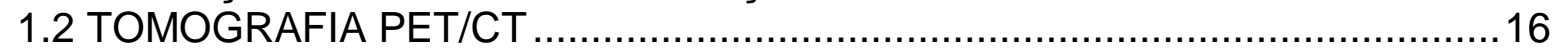

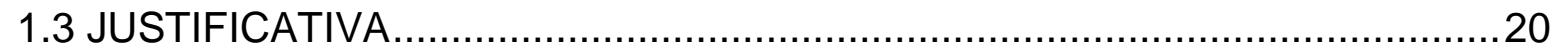

2. OBJETIVOS

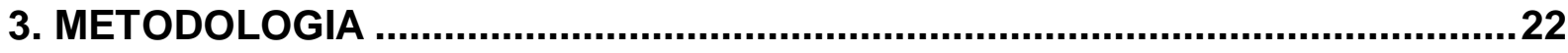

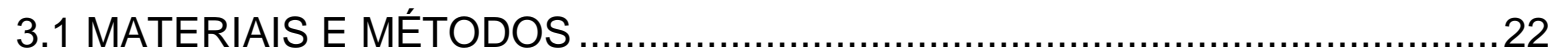

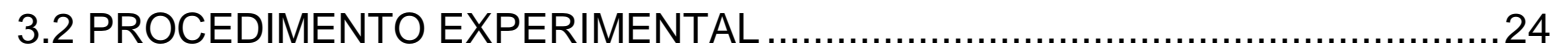

4. RESULTADOS

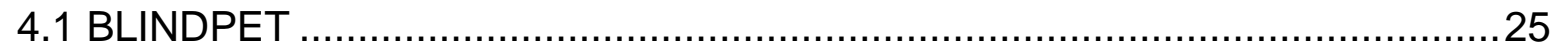

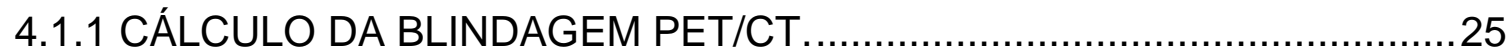

4.1.2 CÁLCULO DA BLINDAGEM ………...........................................2

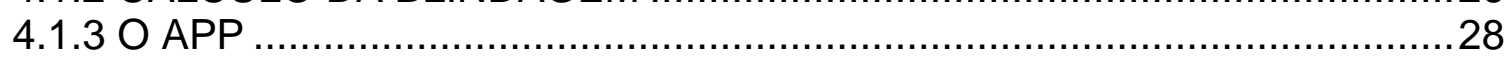

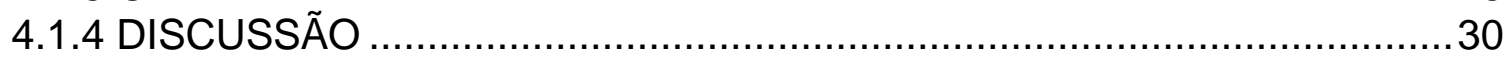

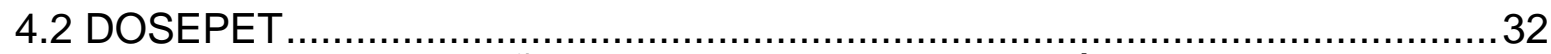

4.2.1 COMPATIBILIZAÇÃO DO VOLUME DE RADIOFÁRMACO COM DOSE DE RADIAÇÃO POR PACIENTE PET/CT. .................................................. 32

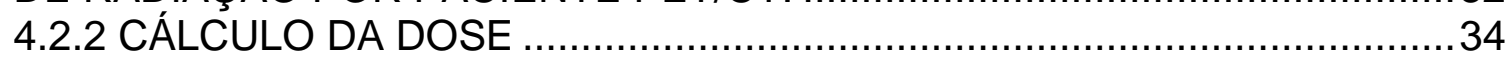

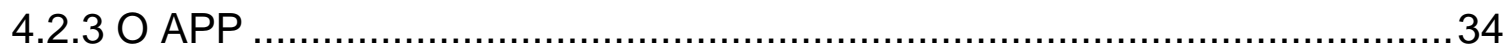

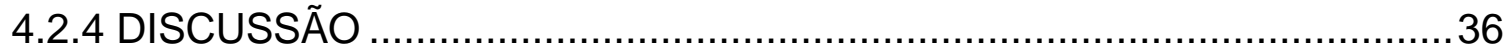

5. CONCLUSÃO

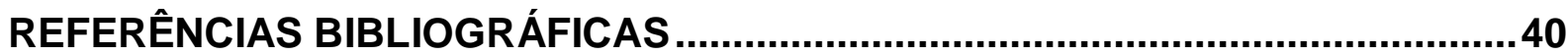

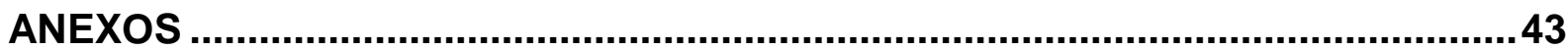




\section{LISTA DE FIGURAS}

Figura 1 - (A) - Cortes coronais da CT, (B) - PET com FDG - ${ }^{18} \mathrm{Fe} \mathrm{(C)} \mathrm{-} \mathrm{imagem} \mathrm{de}$ fusão PET-CT. As setas em (B) e (C) indicam alterações metabólicas diagnosticadas como tumores cancerígenos - Fonte: (Yamaga, 2007). 12

Figura 2 - llustração esquemática do decaimento $\boldsymbol{\beta}+$, (próton $\rightarrow$ nêutron $++\mathbf{1 0 e}+$

v) e da aniquilação pósitron elétron. .16

Figura 3 - (A) forma molecular de glicose. (B) FDG (Fluorodeoxiglucose) $2-\left[{ }^{18} \mathrm{~F}\right]$ flúor-2-deoxi-D-glucose. (Workman 2006).

Figura 4 - Esquema de funcionamento da câmara PET. .18

Figura 5 - Esquema de funcionamento da câmara PET - processamento de eventos. 18

Figura 6 - Interface de Designer do MIT App Inventor 22

Figura 7 - Interface de Programação em blocos do MIT App Inventor. .23

Figura 8 - Imagens da tela do App BindPet. .29

Figura 9 - Layout da sala de uma unidade de PET típica em uma clínica de medicina nuclear. .30

Figura 10 - Imagens da tela do App DosePet. .35

Figura 11 - Imagens da tela do App DosePet. .37 


\section{LISTA DE TABELAS}

Tabela 1 - Propriedades físicas dos radionuclídeos mais utilizados. 17

Tabela 2 - Parâmetro de Monte Carlo para radiações de 511 keV .28

Tabela 3 - Comparação de fatores de transmissão e blindagens sugeridos no relatório AAPM e calculados com BlindPet.

Tabela 4 - Comparação entre níveis, limites e referências de dose de radiação. ....33

Tabela 5 - Exemplo de aplicação do DosePet 36 


\section{LISTA DE ANEXOS}

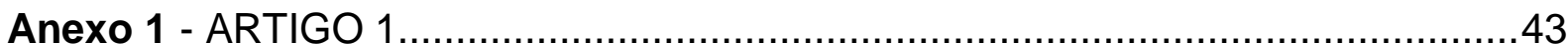

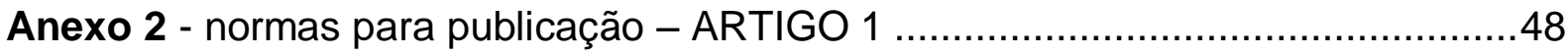

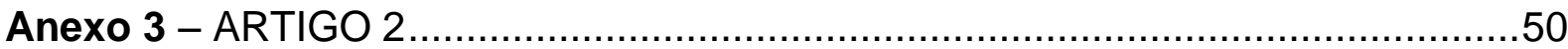

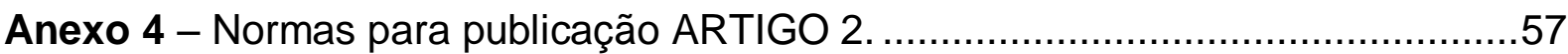

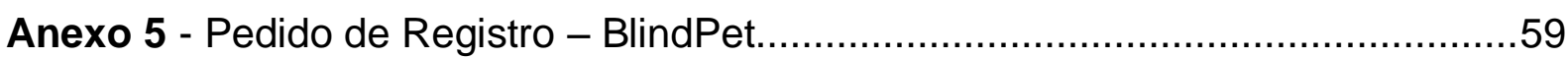

Anexo 6- Pedido de Registro - DosePet ........................................................60 


\section{LISTA DE SIGLAS E SÍMBOLOS}

${ }^{210} \mathrm{~Pb}$ - Isótopo do Chumbo

${ }^{99} \mathrm{Mo}$ - Molibdênio

${ }^{99 \mathrm{~m}} \mathrm{Tc}$ - Tecnécio

A - Massa atômica

App - Aplicativo

CDTN - Centro de Desenvolvimento da Tecnologia Nuclear

CNEN - Comissão Nacional de Energia Nuclear

CRCN-NE - Centro Regional de Ciências Nucleares do Nordeste

CT - Computed Tomography

FDG $-{ }^{18} \mathrm{~F}$-Fluorodesoxiglucose

HFA - Hospital das Forças Armadas

IEN - Instituto de Energia Nuclear

IOE - Indivíduos ocupacionalmente expostos

IOS - iPhone Operating System

IPEN - Instituto de Pesquisas Energéticas e Nucleares

MIT - Massachusetts Institute of Technology

PET - Positron Emission Tomography

PET/CT - Positron Emission Tomography/ Computed Tomography

SPECT - Single Photon Emission Computed Tomography

SUS - Sistema Único de Saúde

UNSCEAR - United Nations Scientific Committee on the Effects of Atomic Radiation Z - Número atômico 


\section{RESUMO}

A PET/CT (Positron Emission Tomographyl Computed Tomography) é uma técnica de aquisição de imagem, de alta resolução da anatomia e fisiologia humana, extremante eficiente no diagnóstico de tumores metabolicamente ativos. A proteção radiológica do PET/CT tem um desafio especial, pois a alta energia de $511 \mathrm{keV}$ dos fótons provenientes da aniquilação de pares diferencia-se de outros exames de diagnósticos que utilizam radiações ionizantes. O cálculo dos requisitos de blindagem para radiação por emissão de pósitrons de em instalações PET/CT proposto em 2006 pela Task Grupo 108 (TG 108), da American Association of Physicists in Medicine (AAMP), pode ser uma tarefa complexa. Nesse trabalho apresentamos dois softwares em forma de Aplicativos (App) que visam contribuir com a Medicina Nuclear. O primeiro, denominado BlindPet, calcula as espessuras das barreiras empregadas na blindagem de instalações destinadas à prática PET/CT e o segundo App, o DosePet, calcula os volumes e doses a serem administradas em pacientes e os resíduos radiação na sala de preparação de PET/CT. Os softwares foram projetados utilizando a ferramenta Web MIT App Inventor2 para plataforma Android. Os aplicativos permitem avaliar a quantidade de radiação ainda existente nas instalações após as aplicações, aumentando a segurança e diminuindo as exposições, além de possibilitar maior eficiência no aproveitamento do radiofármaco.

Palavras Chave: Dose PET/CT, física médica, medicina nuclear, aplicativo, blindagem PET/CT. 


\begin{abstract}
The PET / CT (Positron Emission Tomography / Computed Tomography) is an image capture technique, high resolution of the human anatomy and physiology, extremely efficient in the diagnosis of metabolically active tumors. Radiological protection of the PET / CT has a special challenge because the high energy of 511 $\mathrm{keV}$ photons from the annihilation of pairs differs from other tests diagnostics using ionizing radiation. The calculation of shielding requirements for radiation positron emission of PET / CT facilities proposed in 2006 by the Task Group 108 (TG 108), prepared by the American Association of Physicists in Medicine (AAPM), can be a complex task. In this paper we present two software in the form of Application (App) designed to help in the nuclear medicine. The first, called BlindPet calculates the thicknesses of the shielding barriers used in the installations intended for PET / CT and second App, DosePet calculates the volumes and doses to be administered to patients and residues radiation in the PET/CT preparation room. The software has been designed using the Web Inventor2 MIT App tool for Android platform. The application allows evaluating the amount of radiation still existing in the premises after the applications, increasing security and reducing exposures, and enable greater efficiency in the use of the radiopharmaceutical.
\end{abstract}

Keywords: Dose PET/CT, medical physics, nuclear medicine, application, PET/CT shielding. 


\section{INTRODUÇÃO}

Amplamente utilizada em centros clínicos por todo o mundo, a técnica PET/CT (Positron Emission Tomography/ Computed Tomography) consiste na obtenção de imagens da fisiologia humana, por meio da detecção de rádio traçadores, da atividade metabólica injetados em pacientes (Peet, 2012) combinada às imagens de CT (Computed Tomography). A CT é uma forma de tomografia baseada na detecção de raios $\mathrm{X}$, acoplada a um computador, que reconstrói a imagem topográfica com base nos dados transmitidos durante processo do exame (Marsh, 2013).

Como o nome indica, PET/CT é a fusão de dois tipos de exames diagnósticos, que nos permite obter simultaneamente informações funcionais e anatômicas do corpo, tornando os diagnósticos mais precisos (NBPF, 2016). Na figura a seguir podemos ver um exemplo de cada método de obtenção de imagem e a fusão das duas.
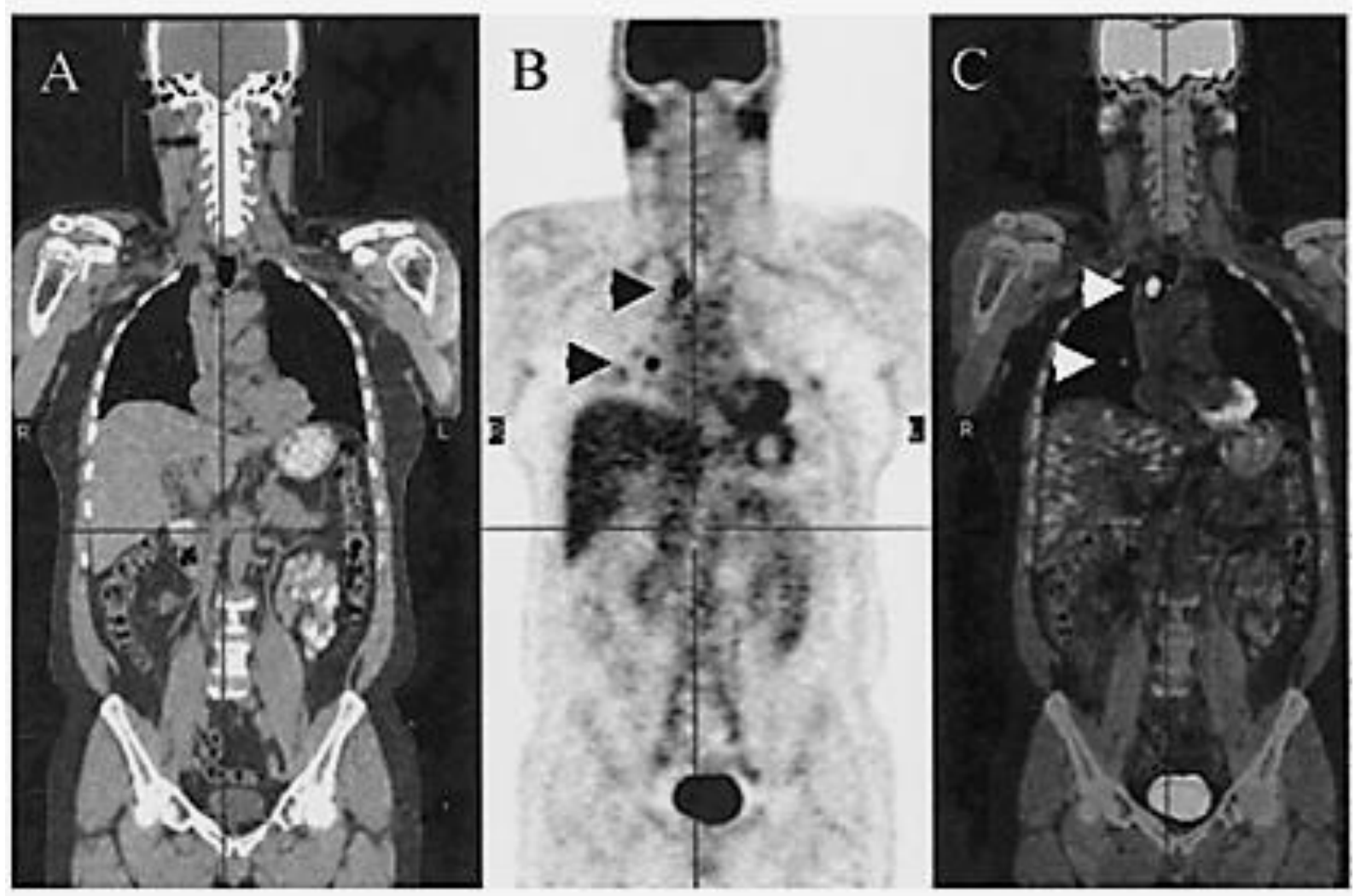

Figura 1 - (A) - Cortes coronais da CT, (B) - PET com FDG $-{ }^{18} \mathrm{Fe} \mathrm{(C)} \mathrm{-} \mathrm{imagem} \mathrm{de} \mathrm{fusão} \mathrm{PET-CT.}$ As setas em (B) e (C) indicam alterações metabólicas diagnosticadas como tumores cancerígenos Fonte: (Yamaga, 2007).

Compostos (ou moléculas) marcados com radionuclídeos, os radiofármacos, seguem caminhos funcionais ou metabólicos específicos nos pacientes. Assim, a 
detecção externa da radiação emitida pelo radiofármaco permite diagnosticar precocemente muitas doenças, visto que as alterações anatômicas, muitas vezes, não se manifestam se não em estágios relativamente avançados, como no caso de diversos tipos de câncer (Robilotta, 2006).

A principal diferença das técnicas PET/CT e CT é que para a PET/CT um rádio traçador é administrado ao paciente. A radiação necessária para coleta das imagens não apresenta risco para os pacientes ou acompanhantes, contudo os indivíduos ocupacionalmente expostos (trabalhadores) precisam ser protegidos, pois o somatório das radiações dos pacientes pode oferecer riscos. A técnica CT separadamente consiste na incidência de raios $X$ sobre alvo (corpo do paciente) e a detecção após a interação para a construção da imagem. Por isso, medidas de contenção da radiação e protocolos de operação que atenuem a absorção de radiação são preocupações constantes, tema deste trabalho e foco de nossa pesquisa. Produzimos ferramentas computacionais que calculam a espessura das barreiras de proteção e que dimensionam o volume de fármaco a ser injetado em cada paciente, detalharemos cada uma dessas ferramentas mais adiante.

\subsection{RADIAÇÃO IONIZANTE E APLICAÇÕES MÉDICAS}

Com a descoberta da radioatividade natural por Henri Becquerel, em 1896, e dos elementos radioativos naturais por Marie e Pierre Curie, em 1898 (descobertas que renderam aos três cientistas o Prêmio Nobel de Física em 1903), a medicina nuclear tem início. Contudo, foi em 1913 que George de Hevesy propôs o princípio do traçador. Ele conseguiu mostrar a absorção e o movimento de nitrato de chumbo, marcado com nuclídeo radioativo $\left({ }^{210} \mathrm{~Pb}\right)$ em plantas, por essa descoberta Hevesy recebeu o Prêmio Nobel de 1943 (Robilotta, 2006).

A partir de 1932 foi possível a produção de radionuclídeos artificiais, devido à criação do primeiro cíclotron, por Ernest O. Lawrwnce (Prêmio Nobel de 1939). Mas só na década de 40 , com os reatores nucleares, os radionuclídeos foram produzidos em quantidades suficientes para uso médico.

Outro fato relevante na história da medicina nuclear foi a introdução do radionuclídeo ${ }^{99 m} \mathrm{Tc}$ (Tecnécio) como marcador (Harper, 1964). O ${ }^{99 \mathrm{~m}} \mathrm{Tc}$ oferece algumas vantagens: ao decair emite um fóton com energia de $140 \mathrm{keV}$, tem uma meia-vida de 6 horas (que é um intervalo de tempo admissível), e principalmente, é 
viável produzi-lo a partir do ${ }^{99}$ Mo (Molibdênio), isto é, pode ser obtido nos próprios centros médicos.

Nas décadas de 60 e 70 diversos avanços computacionais permitiram que um volume de dados maior fosse obtido e analisado, com isso surgiram métodos de reconstrução que possibilitaram as primeiras imagens SPECT (Single Photon Emission Computed Tomography).

De acordo com Robilotta foi a partir de 1990 que a técnica PET se estabeleceu como tecnologia viável nas clínicas nucleares, essa demora é atribuída ao alto custo de implantação e ao curto tempo de meia vida dos radionuclídeos que afeta questões logísticas como a distância do cíclotron e a clínica onde serão feitas as imagens (Robilotta, 2006).

Segundo a CNEN (Comissão Nacional de Energia Nuclear) o setor de medicina nuclear do País, cujos procedimentos para diagnóstico ou terapia utilizam radiofármacos, conta com 432 serviços de medicina nuclear distribuídos por todo 0 território brasileiro, que realizam aproximadamente um milhão e meio de procedimentos de medicina nuclear por ano, sendo que aproximadamente $30 \%$ contam com cobertura do SUS (Sistema Único de Saúde) (CNEN, 2016).

Ainda segundo a CNEN o IPEN (Instituto de Pesquisas Energéticas e Nucleares) é a principal unidade produtora no País, localizado em São Paulo, produz atualmente 38 diferentes radiofármacos, incluindo o FDG- ${ }^{18} \mathrm{~F}$ (fluorodesoxiglucose), além de ser o único produtor de Geradores de ${ }^{99 m}$ Tc. O IEN (Instituto de Energia Nuclear), localizado no Rio de Janeiro, produz o FDG $-{ }^{18} \mathrm{~F}$, iodo-123 ultrapuro e metaiodobenzilguanidina marcada com iodo-123; o CDTN (Centro de Desenvolvimento da Tecnologia Nuclear), em Belo Horizonte, produz o FDG- ${ }^{18} \mathrm{~F}$ e $\mathrm{Na}{ }^{18} \mathrm{~F}$; e o CRCN-NE (Centro Regional de Ciências Nucleares do Nordeste), em Recife, produz somente o FDG- ${ }^{18}$ F. Além desses, o IPEN fornece fios de irídio-192 e sementes de iodo-125, ambos utilizados em tratamentos oncológicos, por meio de procedimentos de braquiterapia (CNEN, 2016).

Para critérios de produção os radiofármacos são divididos em dois grupos de acordo com tempo de meia vida, inferior ou não a 2 horas. O CNEN exerce monopólio de produção nos 37 radiofármacos que possuem meia vida inferior a 2 horas, dentre eles o gerador de ${ }^{99 \mathrm{~m}}$ Tc. O grupo com meia vida superior a 2 horas teve o monopólio da produção e comercialização quebrado pela Emenda 
Constitucional no 49, de 2006, o que permitiu a entrada de produtores privados neste segmento, até essa Emenda a União exercia o monopólio sobre esse grupo. 


\subsection{TOMOGRAFIA PET/CT}

A técnica PET é o mapeamento de órgãos e/ou partes do corpo, ou da atividade metabólica, pela detecção da radiação proveniente de um radionuclídeo. As imagens são obtidas a partir da detecção dos eventos de coincidência, gerados pelo par de fótons emitidos na aniquilação dos pósitrons liberados por decaimentos $\beta$ (beta) provenientes dos traçadores injetados nos pacientes.

Quando um átomo sofre um decaimento $\beta$, sua massa atômica (A) permanece constante, enquanto seu número atômico $(Z)$ varia, aumenta uma unidade no decaimento $\beta^{-}$, ou diminui uma unidade no decaimento $\beta^{+}$. Na figura, a seguir, está representado o decaimento de um próton em; um nêutron, um neutrino e um pósitron, tipo de decaimento responsável pela geração da imagem durante um estudo de PET. O pósitron liberado segue livremente até colidir com um elétron e, como elétron e pósitron são antipartículas, a colisão entre eles resulta em aniquilação mútua, produzindo dois fótons em sentidos opostos e com $511 \mathrm{keV}$ cada, como esquematizado na figura 2 a seguir.

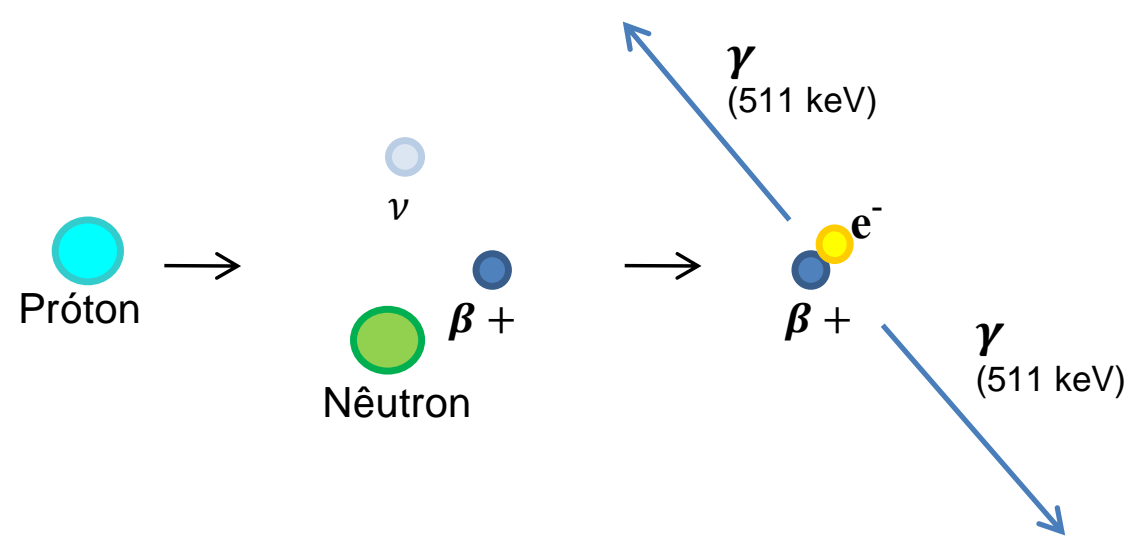

Figura 2 - llustração esquemática do decaimento $\boldsymbol{\beta}^{+}$, (próton $\rightarrow$ nêutron ${ }_{+}{ }_{+1}^{\mathbf{0}} \mathbf{e}+\mathbf{v}$ ) e da aniquilação pósitron elétron.

Radioisótopos emissores de pósitrons utilizados em imagens médicas geralmente têm meias-vidas curtas, como mostra tabela 1, a seguir, e consequentemente, muitos deles, como $\mathrm{O}-15, \mathrm{~N}-13$, e $\mathrm{C}-11$, têm de ser produzidos com um cíclotron no local do exame, a fim de dispor de quantidades clinicamente úteis (Madsen, 2006). 
Tabela 1 - Propriedades físicas dos radionuclídeos mais utilizados.

\begin{tabular}{llcc}
\hline Radionuclídeo & Meia-vida & Tipo de decaimento & Energia dos fótons emitidos (keV) \\
\hline${ }^{11} \mathrm{C}$ & $20,4 \mathrm{~min}$ & $\beta+$ & 511 \\
${ }^{13} \mathrm{~N}$ & $10,0 \mathrm{~min}$ & $\beta+$ & 511 \\
${ }^{15} \mathrm{O}$ & $2,0 \mathrm{~min}$ & $\beta+$ & 511 \\
${ }^{18} \mathrm{~F}$ & $109,8 \mathrm{~min}$ & $\beta+, \mathrm{EC}$ & 511 \\
${ }^{64} \mathrm{Cu}$ & $12,7 \mathrm{~h}$ & $\beta-, \beta+, \mathrm{EC}$ & 511,1346 \\
${ }^{68} \mathrm{Ga}$ & $68,3 \mathrm{~min}$ & $\beta+, \mathrm{EC}$ & 511 \\
${ }^{82} \mathrm{Rb}$ & $76 \mathrm{~S}$ & $\beta+, \mathrm{EC}$ & 511,776 \\
${ }^{124} \mathrm{I}$ & $4,2 \mathrm{~d}$ & $\beta+, \mathrm{EC}$ & $511,603,1693$
\end{tabular}

O FDG ${ }^{18} \mathrm{~F}$ é um dos radiofármacos mais utilizados para essa finalidade, por acumular-se em concentração elevada em tumores metabolicamente ativos, bem como no cérebro e no miocárdio (Krabbe, 2011 - Nestle, 2006). O FDG $-{ }^{18} \mathrm{~F}$ tem uma estrutura e um comportamento bioquímico, de absorção pelos tecidos de alto metabolismo, muito semelhante à glicose, note a semelhança entre as moléculas na figura 3 a seguir:

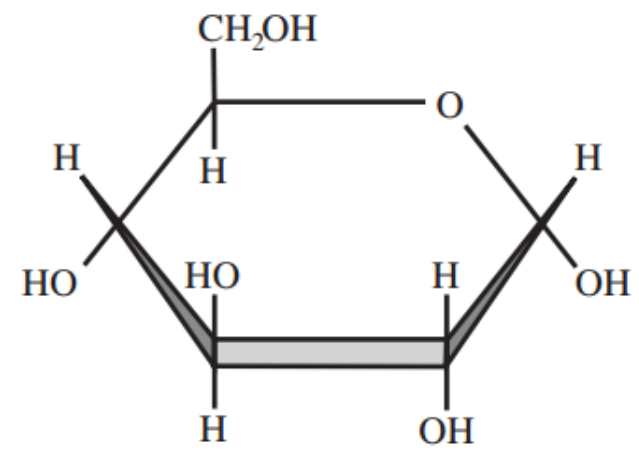

(A)

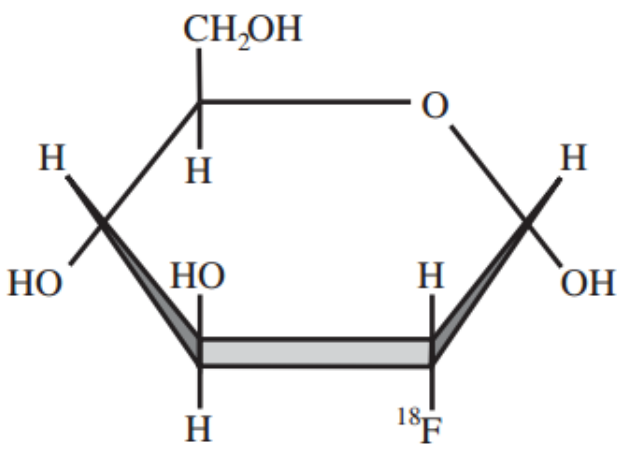

(B)

Figura 3 - (A) forma molecular de glicose. (B) FDG (Fluorodeoxiglucose) 2- $\left[{ }^{18} \mathrm{~F}\right]$ flúor-2-deoxi-Dglucose. (Workman 2006).

Com uma meia vida de aproximadamente 110 minutos, as partículas $\beta+$ emitidas pelo ${ }^{18} \mathrm{~F}$ têm energia de $511 \mathrm{keV}$ e possuem um alcance de $1,0 \mathrm{~mm}$ a 2,0 $\mathrm{mm}$, e por isso são excepcionais para diagnóstico de metabolismo e imagem de tumores (Henríquez, 2011).

As imagens são adquiridas a partir da colimação eletrônica que registra eventos de coincidência, ou seja, pares de fótons provenientes da aniquilação pósitrons elétron dentro de um intervalo de tempo muito curto. As figuras 4 e 5 ilustram esses eventos para um sistema dedicado. 


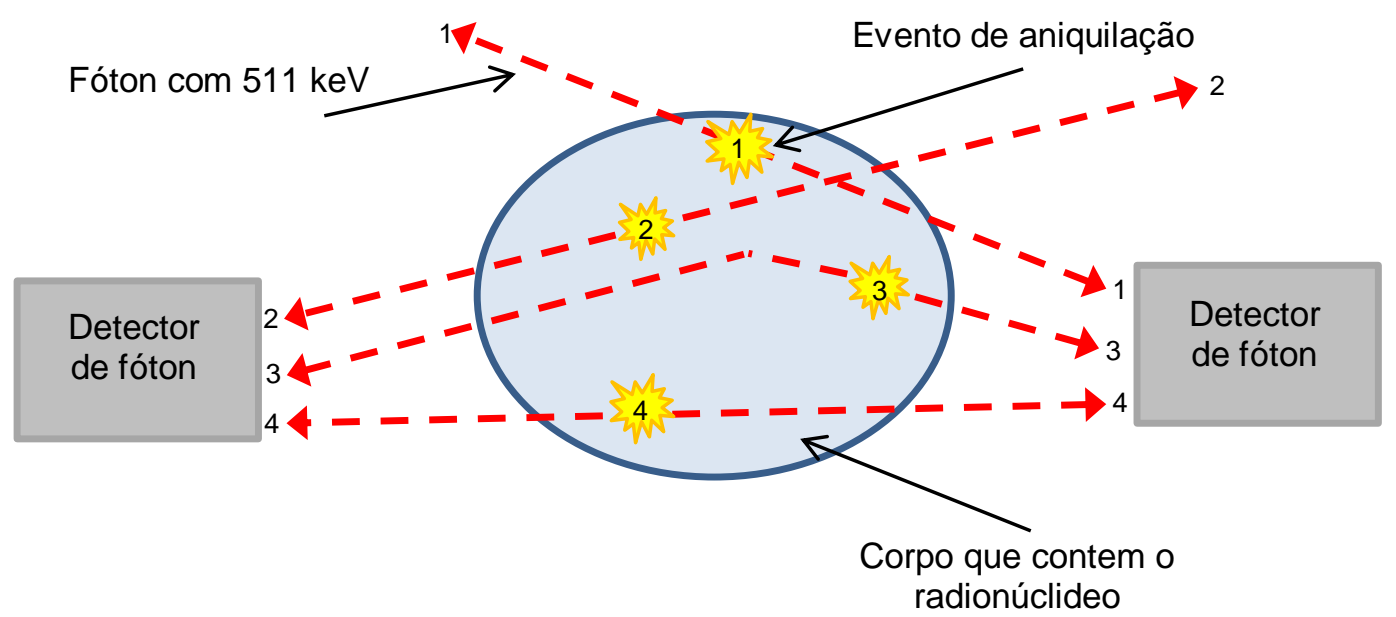

Figura 4 - Esquema de funcionamento da câmara PET.

Vista do corte a ser mapeado pela CT, os eventos de aniquilação estão representados por estrelas amarelas e o par de fótons é representado por linhas tracejadas vermelhas. Os eventos de aniquilação e o par de fótons liberado estão numerados com o mesmo número.

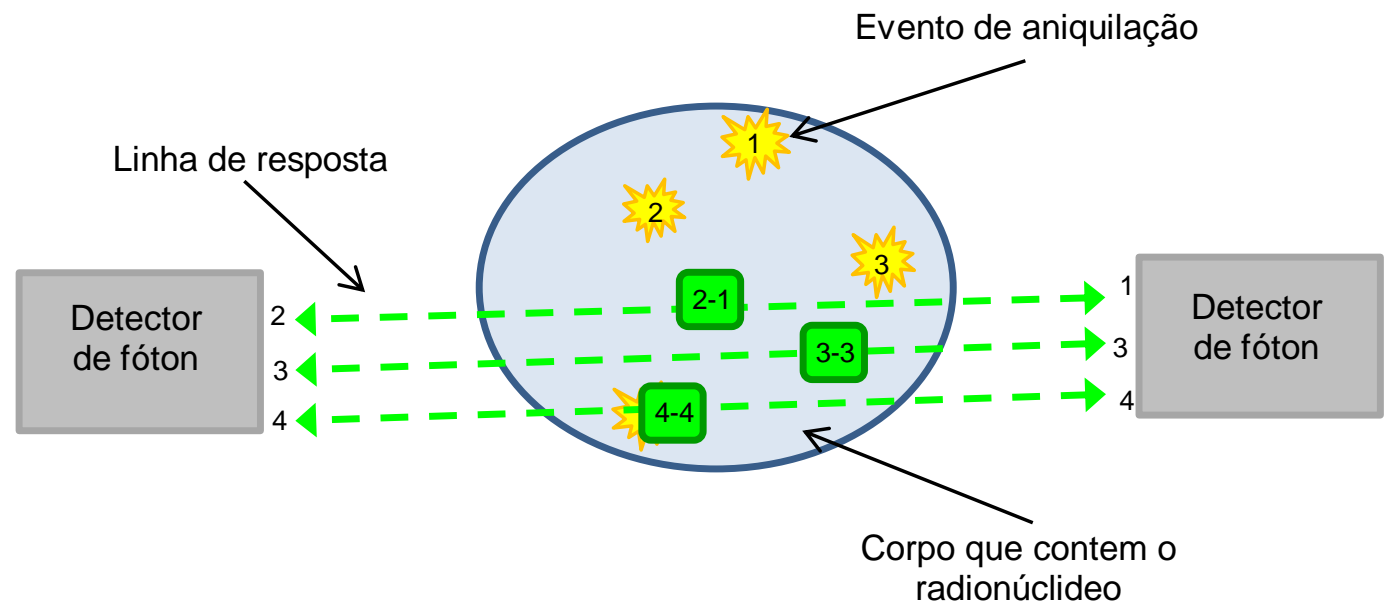

Figura 5 - Esquema de funcionamento da câmara PET - processamento de eventos. De verde e tracejada são as linhas de resposta traçadas pelo tomógrafo, os quadrados verdes são pontos interpretados pelo sistema como fontes de eventos de aniquilação. São denominados os eventos: 2-1 aleatório, 3-3 espalhado e 4-4 verdadeiro.

Como ilustrado na figura 5, o equipamento traça linhas hipotéticas entre os sensores simultaneamente acionados para localizar a origem dos fótons (linha tracejada verde). A linha formada entre os dois detectores que acionados pelos fótons é definida como linha de resposta, se os dois fótons detectados provierem de uma mesma aniquilação, sem interagir com o meio, o evento é chamado de verdadeiro (evento 4-4), e o local de aniquilação estará sobre a linha de resposta. Se os fótons forem originados de uma mesma aniquilação, porém um deles tiver interagido com o meio, o local de aniquilação não estará mais sobre a linha de resposta e o evento é denominado espalhado (evento 3-3). Se ambos os fótons se 
originarem de aniquilações diferentes, o par detectado definirá uma linha de resposta errada, resultando em um evento aleatório (evento 2-1).

Várias técnicas são utilizadas para evitar equívocos na interpretação das imagens, são ações no hardware e no software (ou no algoritmo de interpretação). Essas técnicas são definidas para desconsiderar os eventos espalhados e aleatórios e construir a imagem a partir dos eventos verdadeiros. Em geral os sistemas permitem aquisição de imagens 2D ou 3D, são os algoritmos de tratamento dos dados (e a capacidade física processamento - hardware) que definem o tipo de imagem que cada aparelho é capaz de gerar. 


\subsection{JUSTIFICATIVA}

A proteção radiológica na técnica PET (Pósitron Emission Tomography) tem um desafio especial, pois a alta energia de $511 \mathrm{keV}$ dos fótons provenientes da aniquilação de pares diferencia-se de outros exames de diagnósticos que utilizam radiações ionizantes (Antic, 2013). Nesse quadro, iniciativas que possam melhorar as barreiras de proteção radioativa ou que reduzam o tempo de exposição dos trabalhadores e transeuntes nos laboratórios são importantes para minimizar a exposição a doses elevadas. Por esse motivo, desenvolvemos dois aplicativos, BlindPet e DosePet, com o objetivo de reduzir a exposição a radiação pelo uso de blindagens, e otimizar o planejamento radio farmacêutico.

O BlindPet é um software compilado para smartphones (App - aplicativo), concebido para auxiliar profissionais que trabalham com projeto de instalações para o uso de PET/CT, permitindo manipular variáveis com respostas instantâneas e sem que Ihes sejam exigidos cálculos complexos. O software destina-se às profissionais qualificados que desejem projetar instalações para o uso de PET/CT, permitindo manipular variáveis de: dimensão, posicionamento, fluxo de pacientes, entre outros parâmetros que necessitem ser analisados.

O App DosePet foi criado para auxiliar o farmacêutico no cálculo do volume de medicamento necessário para que cada paciente receba a dosagem, no caso a atividade, exata de medicação. Esse App é importante, pois, ele permite simular instantaneamente a relação entre volume e dosagem (atividade) do radiofármaco ao longo do tempo, diminuindo o tempo de manipulação para o preparo das doses e minorando o esperdício do radiofármaco, aumentando assim o nível de segurança nos laboratórios e a otimização do uso do radiofármaco. 


\section{OBJETIVOS}

Para Arce, as simulações em Física Médica são um conjunto de ferramentas de software que permitem ao usuário flexibilidade de adaptação para aplicação específica sem a necessidade de o usuário dominar linguagem de script (Arce, 2009), ou seja, é utilizar a tecnologia como mecanismo facilitador. Nosso objetivo foi criar aplicativos móveis que realizem os cálculos: 1) de barreira para áreas controladas e não controladas; de blindagem para quartos adjacentes; e das taxas de exposição de pacientes e 2) o cálculo do volume de medicamento necessário para que cada paciente receba a dose exata de medicação.

A plataforma escolhida para o projeto foi o Android, por ser de código aberto e de grande popularidade, para a programação utilizamos a ferramenta web MIT App Inventor2 na linguagem JAVA. 


\section{METODOLOGIA}

\subsection{Materiais e métodos}

O MIT App inventor é uma ferramenta web de programação visual, criada pelo Professor Hal Abelson do MIT (Massachusetts Institute of Technology) e Mark Friedman do Google, ele funciona como um serviço web administrado pela equipe do Centro do MIT para Mobile Learning - uma colaboração de Ciência do MIT Computação e Laboratório de Inteligência Artificial e do MIT Media Lab. Trata se de uma ferramenta do tipo "arrastar e soltar", para projetar e construir aplicativos móveis para o Android, ele transforma a língua de codificação baseada em texto em blocos de construção visual (MIT App Invento, 2016). A metodologia de programação em blocos permite que o desenvolvedor se concentre na lógica para a programação em vez de a sintaxe da linguagem de codificação.

A interface de usuário do App Inventor consiste de duas partes: um designer figura 6, para selecionar os componentes de o aplicativo, e um editor de blocos figura 7, para definir o comportamento do aplicativo.

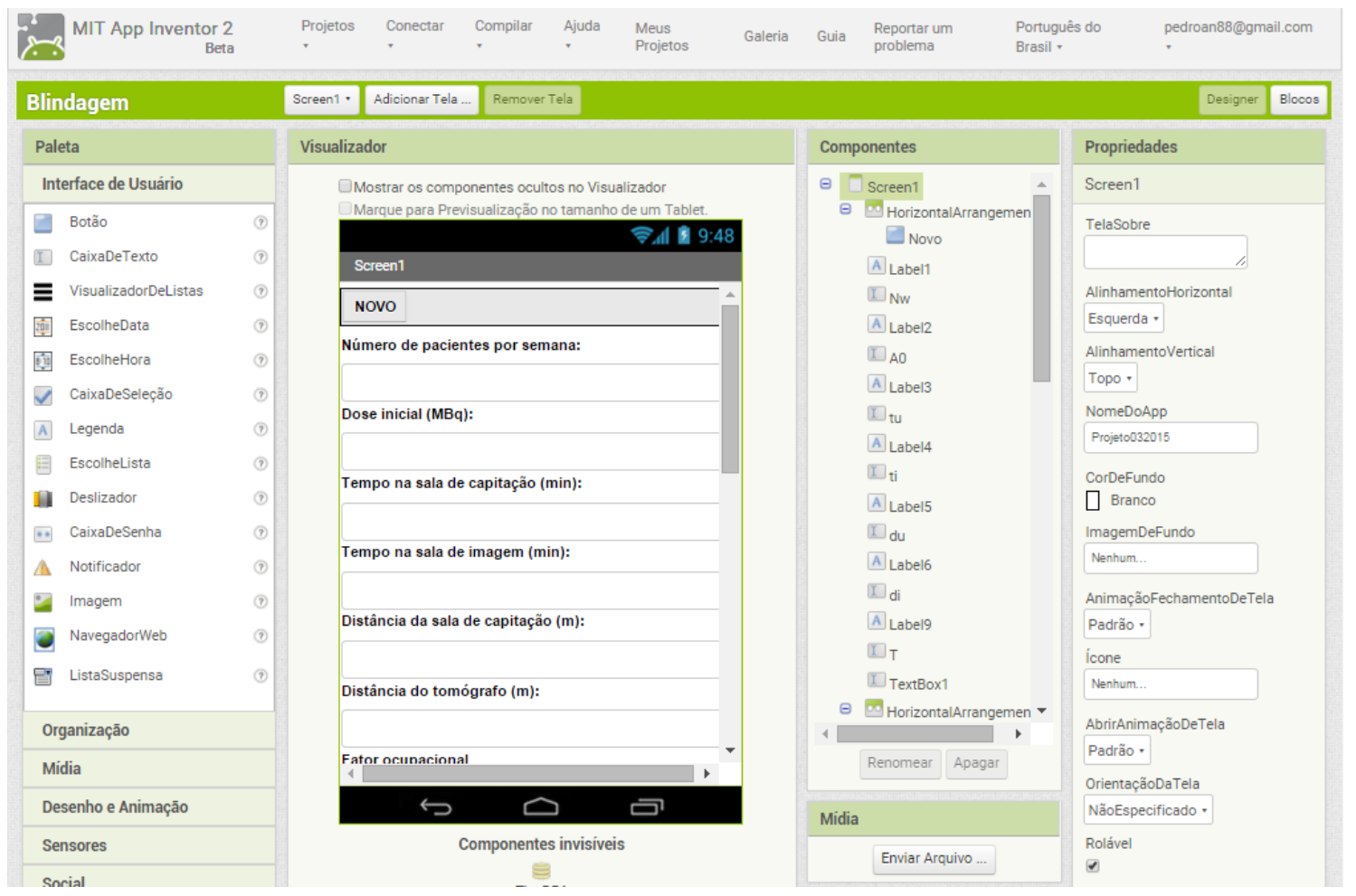

Figura 6 - Interface de Designer do MIT App Inventor. 


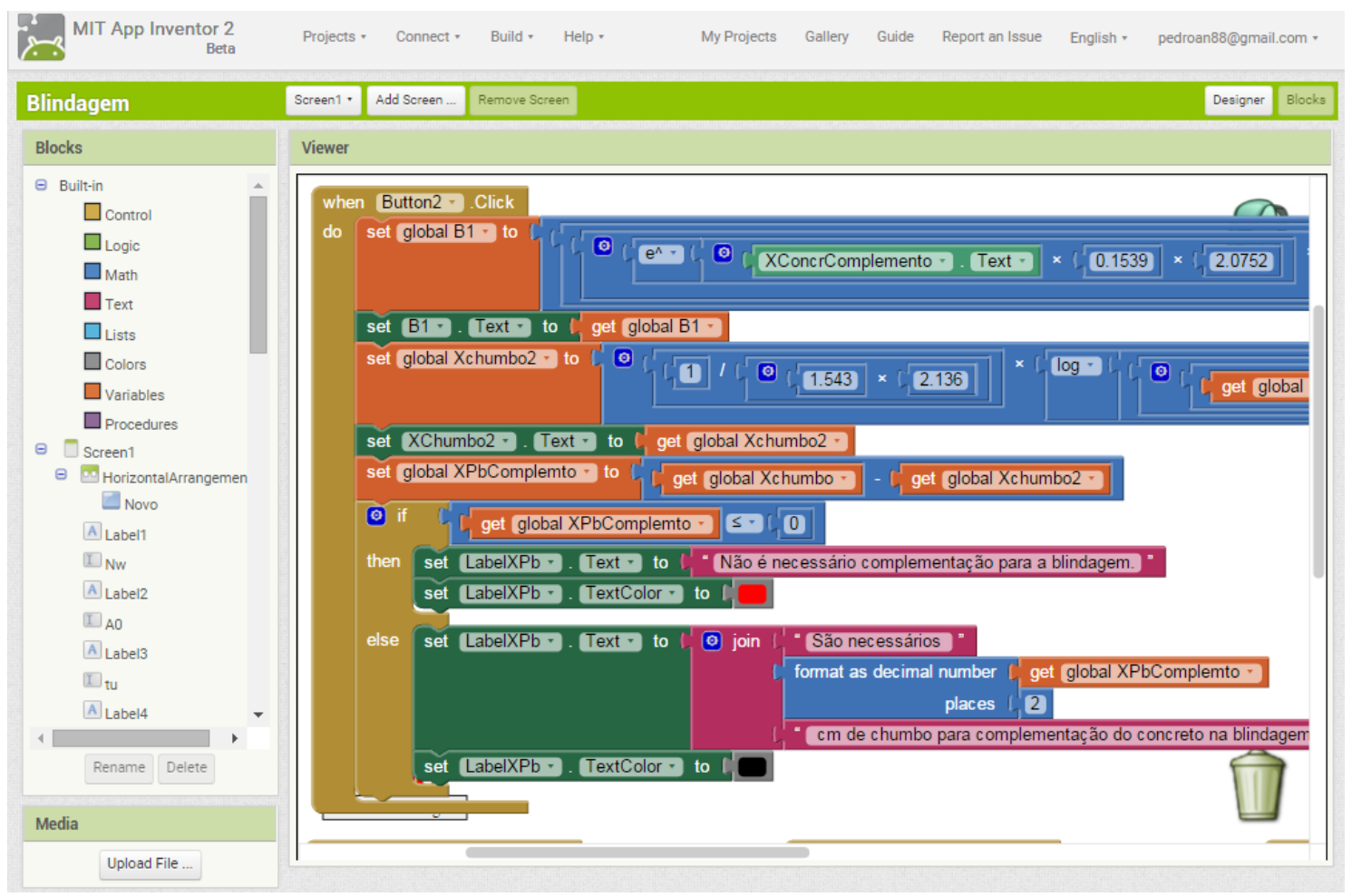

Figura 7 - Interface de Programação em blocos do MIT App Inventor.

De acordo com o MIT App Inventor Team em 2015, a comunidade MIT App Inventor já era composta por cerca de 3 milhões de usuários, representando 195 países (MIT App Inventor, 2016). O MIT App Inventor é ensinado para um público amplo, que vão desde escolas primárias a estudantes universitários. Relatórios sobre cursos ministrados retratam o App Inventor sendo usado para criar aplicativos muito diversos, que executam funções como: desencorajar motoristas a trocarem mensagens de texto enquanto dirigem, acompanhar o trajeto de ônibus escolares, organizar serviços comunitários de limpeza (Xie, 2015) ou sistemas mais complexos como o diagnóstico diferencial de cardiopatias congênitas (Mourato, 2013).

Os aplicativos criados com o App Inventor só funcionam em dispositivos com sistema operacional Android. Concentrando em um único sistema operacional a ferramenta oferece mais funcionalidade, permitindo acesso a mais recursos do dispositivo móvel e minimizando os erros. Outro benefício da limitação do sistema operacional é possibilidade de compartilhar os aplicativos em lugar acessível ao público e sem ter que comprar licença de desenvolvedor, o que é feito por meio da Google Play Store.

Escolhemos trabalhar com o App Inventor por ser uma plataforma gratuita e de fácil acesso. O ambiente de desenvolvimento do App Inventor é suportado para 
os sistemas operacionais Mac OS X, o GNU / Linux e Windows, e os aplicativos resultantes podem ser instalados em qualquer aparelho Android que tenha em execução o Android 1.5 (Cupcake) ou mais recente.

\subsection{Procedimento experimental}

Os softwares foram desenvolvidos utilizando a metodologia Extreme Programming $(\mathrm{XP})$, por ser ágil para equipes pequenas e médias que desenvolvem softwares baseados em requisitos vagos e que se modificam rapidamente (Beck, 1999). Seguindo essa metodologia os seguintes passos foram percorridos:

a) Especificação do Software: Revisão literária para definição das funcionalidades (requisitos) e das restrições do software.

b) Projeto e Implementação do Software: compilação do código fonte do software, por meio de mecanismo de blocos (MIT App Inventor2), de acordo com as especificações.

c) Validação do Software: Realização de testes sobre funcionalidade, confiabilidade, usabilidade, eficiência, manutenibilidade e portabilidade.

d) Evolução do Software: Os dados coletados na fase anterior foram utilizados para correção de falhas e inserção de melhorias sugeridas pelos profissionais do HFA. Além disso foram projetadas alterações como a transcrição do App para IOS (iPhone operating system). 


\section{RESULTADOS}

\subsection{BLINDPET}

\subsubsection{CÁLCULO DA BLINDAGEM PET/CT.}

A blindagem para instalações PET e PET/CT possui um desafio especial, pois a alta energia liberada (511 keV) na aniquilação de pósitrons é maior que a energia liberada em outros procedimentos de imagem. Por isso, é necessário que existam blindagens radiológicas nas paredes, no teto e no piso.

Uma vez que o paciente torna-se a fonte radioativa após o radiofármaco ser injetado, tem de se considerar todo o tempo, e o espaço, que esse indivíduo permanecerá na clínica.

O FDG $-{ }^{18} \mathrm{~F}$ é um marcador não específico para o metabolismo normalmente absorvido no cérebro, no coração, na medula óssea, no intestino, nos rins, nos músculos em atividade e em tumores metabolicamente ativos, o que o torna um agente de diagnóstico. Contudo, após a administração do FDG - ${ }^{18} \mathrm{~F}$ o paciente permanece em repouso, deitado ou sentado, em uma sala de espera entre 30 e 90 min, dependendo do tipo de diagnostico e da instalação. Esse período de repouso do paciente na sala de preparação é importante para diminuir a absorção do FDG ${ }^{18} \mathrm{~F}$ pelos músculos. Por esse motivo, a sala de preparação do paciente é um requisito de todas as instalações PET, e está prevista no planejamento de segurança da radiação.

Após o período de captação, cerca de 15 a 20\% da atividade administrada é excretada pela urina nas primeiras 2 horas. Ou seja, além da sala de preparo é necessário que o paciente também tenha um banheiro exclusivo. Isso precisa ser previsto para cada paciente, afinal, as instalações quase sempre atentem diversos pacientes simultaneamente.

Em média, um paciente fica entre 15 e 60 minutos na sala de imagem, sendo liberado imediatamente após o exame. Se por algum motivo o paciente é mantido na clínica, a área de espera também precisa ser incluída no planejamento de segurança contra radiação. Devido à elevada penetração da radiação, proveniente do decaimento $\beta$, todas as áreas por onde transita o paciente devem ser considerada no calculo para blindagem. Isto inclui laje e piso do laboratório PET, bem como áreas adjacentes no mesmo andar (Masden, 2006). 
A dose de radiação absorvida por um indivíduo é medida no sistema internacional em joule por quilograma $(\mathrm{J} / \mathrm{kg})$, denominada sievert (Sv). De acordo com a CNEN (Comissão Nacional de Energia Nuclear), o limite de dose anual não pode ultrapassar $1 \mathrm{mSv}$ para indivíduos públicos e $20 \mathrm{mSv}$ para indivíduos ocupacionalmente expostos (CNEN, 2011). A dose de radiação administrada ao paciente não é suficiente para causar danos à ele ou às pessoas que convivem com ele, contudo a equipe de saúde que realiza esses exames - composta, por indivíduos ocupacionalmente expostos (IOE) - necessita de proteção, pois o somatório das radiações provenientes de vários pacientes e por vários dias pode ser nociva, por isso a blindagem nos laboratórios é tão importante. As barreiras de proteção também ajudam a proteger o público em geral que precisa transitar nas proximidades das instalações, afinal ninguém deve receber, desnecessariamente, doses de radiação acima do preconizado.

Os leitores interessados no aplicativo podem entrar em contato com os autores através do e-mail pedroan88@gmail.com.

\subsubsection{CÁLCULO DA BLINDAGEM}

Para estimar a espessura da barreira de proteção $(x)$ o relatório AAPM TG 108 da Associação Americana de Físicos Médicos tornou-se um guia para calcular a blindagem PET/CT. Algumas aproximações são adotadas nos cálculos, baseadas nos valores experimentais sugeridos pelo AAPM TG -108, tais como: a taxa de dose adequada constante para $\mathrm{F}-18$ de $0,143 \mu S v \mathrm{~m}^{2} / M B q h$, e a taxa de dose associada a $37 \mathrm{MBq}(1 \mathrm{mCi})$ de $\mathrm{F}-18$ de $5,3 \mu \mathrm{Sv} / \mathrm{h}$, isso a $1 \mathrm{~m}$ de uma fonte pontual não blindada (Masden, 2006).

A atividade é uma grandeza definida por

$$
A=\frac{d N}{d t}
$$

onde dN é o valor esperado do número de transições nucleares espontâneas daquele estado de energia no intervalo de tempo dt. A unidade no sistema internacional é denominada Becquerel $(\mathrm{Bq})$, contudo comercialmente a unidade mais utilizada é Curie $(\mathrm{Ci})$, sendo $1 \mathrm{MBq}=37,012 \mathrm{mCi}$.

Devido parte da radiação ser absorvida pelo corpo a dose emitida pelo paciente é de $0,092 \mu S v m^{2} / M B q h$ imediatamente após a administração, esse 
dado é sugerido pelo AAPM TG -108 (Masden, 2006) baseado em teste feito pelo grupo. Isto corresponde a um fator eficaz de absorção do corpo de 0,36 , o que está de acordo com o fator de absorção total do corpo de 0, 34 por 500 fótons keV (Snyder, 1969).

Devido à meia vida curta dos radiotraçadores PET, a dose instantânea de radiação, $D(t)$, diminui exponencialmente em função do tempo. $O$ fator de redução da dose, $R_{t}$, é calculado com a seguinte relação:

$$
R_{t}=\frac{D(t)}{D(0) \times t}=1,443 \times\left(\frac{T_{1 / 2}}{t}\right) \times\left[1-\exp \left(\frac{-0,693 t}{T_{1 / 2}}\right)\right]
$$

Como já mencionando, os pacientes precisam aguardar em uma sala de repouso entre 30 e 90 minutos antes da captação de imagens, os valores de $R_{t}$ são necessários para o calculo das doses totais de radiação, $D\left(t_{\mathrm{U}}\right)$, à uma distância $\mathrm{d}(\mathrm{m})$ de um paciente durante o tempo de captação (tu), o valor de $D\left(t_{u}\right)$ é:

$$
D\left(t_{U}\right)=0,092 \frac{\mu S v m^{2}}{M B q h} \times A_{0}(M B q) \times t_{U}(h) \times \frac{R_{t U}}{[d(m)]^{2}}
$$

Se $N_{w}$ é o número de pacientes atendidos por semana, a dose total semanal é de:

$$
D\left(t_{U}\right)_{N w}=0,092 \frac{\mu S v m^{2}}{M B q h} \times A_{0}(M B q) \times t_{U}(h) \times \frac{R_{t U}}{[d(m)]^{2}} \times N_{w}
$$

Para analisar um ambiente precisamos considerar seu fator ocupacional, T, entre 0 e $1(100 \%)$ e a dose limite semanal, $P$, que esse ambiente pode receber. No Brasil $\mathrm{P}=20 \mu S v$ para áreas não controladas, que correspondem a $1 \mathrm{mSv} / \mathrm{ano}$ que é o limite para o público em gera e $\mathrm{P}=100 \mu S v$ para áreas controladas, valores estabelecidos pela CNEN. O AAPM TG -108 ainda define o fator de transmissão, B, como:

$$
\begin{gathered}
B=\frac{P}{T \times D\left(t_{U}\right)_{N w}} \\
B=\frac{218 \times[d(m)]^{2}}{\left[T \times N_{w} \times A_{0}(M B q) \times t_{U}(h) \times R_{t U}\right]} \\
B=\frac{1090 \times[d(m)]^{2}}{\left[T \times N_{w} \times A_{0}(M B q) \times t_{U}(h) \times R_{t U}\right]}
\end{gathered}
$$

Sendo a equação (6) para áreas não controladas e (7) para áreas controladas.

Se considerarmos que não há nenhuma blindagem no tomógrafo, o cálculo de blindagem para a sala de tomografia é semelhante ao cálculo da área de captação. 
Devido ao tempo exigido na fase de fixação entre a administração do radiofármaco e a imagem real, a atividade no paciente diminuiu de:

$$
F_{U}=\exp \left(\frac{-0,693 \times t_{U}}{T_{1 / 2}}\right)
$$

onde $F_{U}$ é o fator de decaimento da sala de captação expresso em mSv. Logo, a dose semanal $\left(D\left(t_{I}\right)_{N w}\right)$ e o fator de transmissão (B) a uma distância d a partir da fonte na sala de tomografia são calculados como:

$$
\begin{gathered}
D\left(t_{I}\right)_{N w}=0,092 \frac{\mu S v m^{2}}{M B q h} \times A_{0}(M B q) \times F_{U} \times t_{I}(h) \times \frac{R_{t I}}{[d(m)]^{2}} \times N_{w} \\
B=\frac{12,8 \cdot P \cdot d^{2}}{T \cdot N_{w} \cdot A_{0} \cdot F_{U} \cdot t_{I} \cdot R_{t I}}
\end{gathered}
$$

onde $t_{l}$ é o tempo na sala de imagem e $R_{t \mid}$ é o fator de redução da dose no tempo de imagem.

Conhecendo o fator de transmissão é possível utilizar o método empírico, denominado Monte Carlo, para estimar a espessura da barreira de proteção com a seguinte relação:

$$
x=(1 / \alpha \gamma) \ln \left\{\left[B^{-\gamma}+(\beta / \alpha)\right] /[1+(\beta / \alpha)]\right\}
$$

onde $\alpha, \gamma$ e $\beta$ são parâmetros específicos que variam com tipo de material utilizado na barreia e o valor de radiação esperada, como mostra a tabela 2 a seguir:

Tabela 2 - Parâmetro de Monte Carlo para radiações de 511 keV.

\begin{tabular}{clll}
\hline Material de Blindagem & $\alpha\left(\mathrm{cm}^{-1}\right)$ & $\beta\left(\mathrm{cm}^{-1}\right)$ & $\gamma$ \\
\hline Chumbo & 1,543 & $-0,4408$ & 2,136 \\
Concreto & 0,1539 & $-0,1161$ & 2,0752
\end{tabular}

\subsubsection{O APP}

No BlindPet unificamos todas as etapas do cálculo para blindagem e substituímos as tabelas de aproximação pelo cálculo efetivo da blindagem sugerida pelo relatório AAPM TG -108. O usuário deve inserir as seguintes variáveis: número de pacientes por semana, dose inicial para cada paciente, o tempo na sala de captação, tempo na sala de imagem, as distâncias da sala de captação e do tomógrafo, o fator ocupacional e o tipo de área. O App calcula e fornece os parâmetros de doses, o fator de transmissão e as espessuras de blindagem para concreto e chumbo, como mostra a figura a seguir. 


\begin{tabular}{l}
\hline Screen1 \\
Novo \\
Número de pacientes por semana: \\
40 \\
Dose inicial (MBq): \\
\hline 555 \\
Tempo na sala de capitação $(\mathrm{min}):$ \\
\hline 60 \\
Tempo na sala de imagem $(\mathrm{min}):$ \\
\hline 30 \\
\hline Distância da sala de capitação $(\mathrm{m}):$ \\
\hline 8 \\
\hline Distância do tomógrafo $(\mathrm{m}):$ \\
\hline 5 \\
\hline Fator ocupacional \\
\hline$\quad \checkmark$ \\
\hline
\end{tabular}

(A)

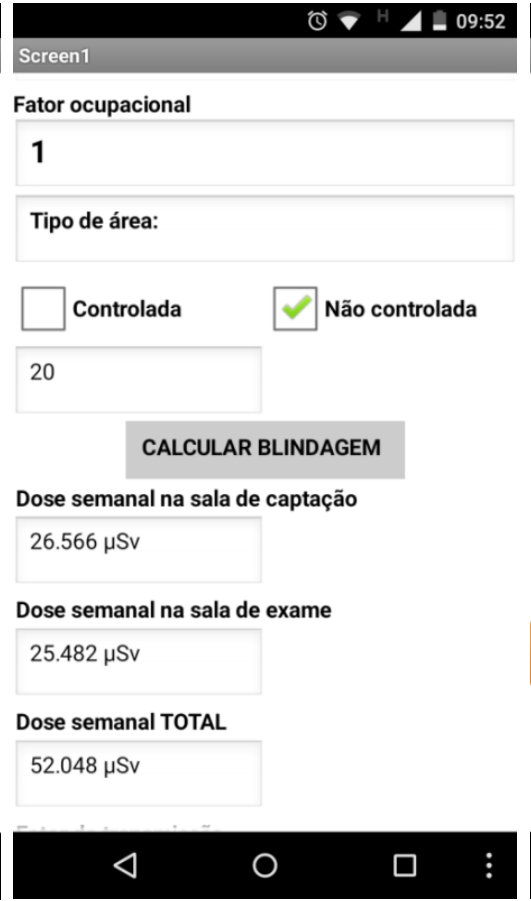

(B)

Figura 8 - Imagens da tela do App BindPet.

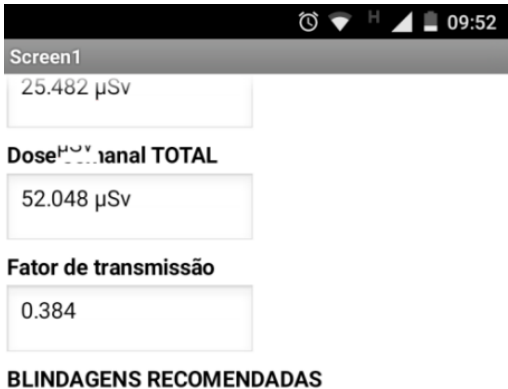

Concreto: $10.27 \mathrm{~cm}$

Chumbo: $0.71 \mathrm{~cm}$

COMPLEMENTANDO CONCRETO COM CHUMBO: Camada de concreto já existente $(\mathrm{cm})$ :

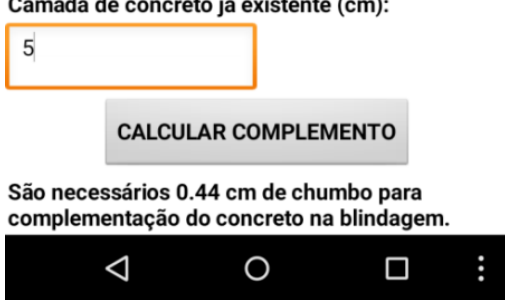

(C)

Outra peculiaridade do App é a possibilidade do cálculo da espessura da barreira de chumbo complementar, que deve ser aplicada em uma barreira de concreto pré-existente, situação recorrente no cálculo da blindagem, uma vez que no Brasil o concreto é largamente utilizado na parte estrutural dos edifícios. 


\subsubsection{DISCUSSÃO}

\section{VALIDAÇÃO DO SOFTWARE}

Para análise dos resultados apresentados pelo BlindPet, repetimos os cálculos dos exemplos propostos no relatório AAPM TG -108, a seguir está uma planta fictícia proposta como exemplo no relatório AAPM TG -108, figura a seguir.

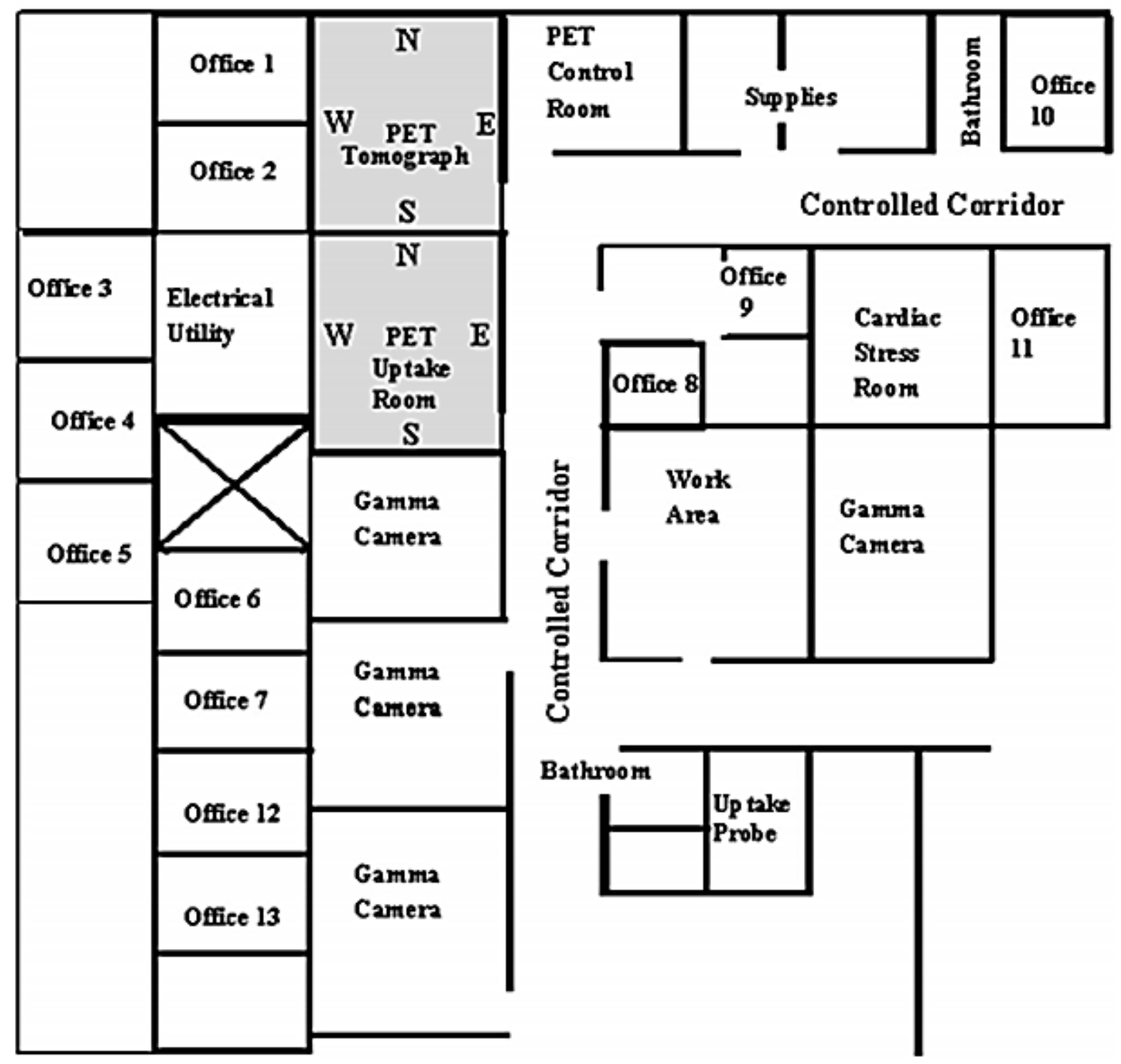

Figura 9 - Layout da sala de uma unidade de PET típica em uma clínica de medicina nuclear.

Além da planta todos os parâmetros necessários para o cálculo foram fornecidos no relatório AAPM TG -108, não foram registradas variações significativas entre os valores de fator de transmissão calculados pelo App e os calculados no relatório AAPM TG -108, como apresentado na Tabela 3 a seguir. 
Tabela 3 - Comparação de fatores de transmissão e blindagens sugeridos no relatório AAPM e calculados com BlindPet.

\begin{tabular}{ccc}
\hline & \multicolumn{2}{c}{ Fator de Transmissão } \\
\hline Comodo & AAPM & BlindPet \\
\hline Sala 1 & 0,206 & 0,206 \\
Sala 2 & 0,169 & 0,169 \\
Sala 3 & 0,5 & 0,505 \\
Sala 4 & 0,629 & 0,637 \\
Sala 5 & 0,685 & 0,695 \\
Sala 6 & 0,872 & 0,885 \\
Sala 8 & 0,442 & 0,448 \\
Sala 9 & 0,685 & 0,693 \\
Sala de Controle PET & 0,817 & 0,814 \\
Câmara Gama & 0,503 & 0,512
\end{tabular}

Cada sala da Tabela 3 representa um office na figura 9. Não estão representados todos os cômodos da planta na tabela, constam apenas os valores fornecidos no exemplo do relatório AAPM TG -108.

As variações encontradas entre o fator de transmissão calculado pelo AAPM TG -108 e o BlindPet são inferiores a 1, 9\%, atribuímos essas pequenas diferenças a questões de arredondamento decorrentes de casas decimais e precisão. Já as espessuras calculadas pelo APP estão todas de acordo com as estimativas da AAPM, baseado nos dados apresentados na tabela 3 concluímos que o BlindPet fornece ao usuário um cálculo instantâneo e mais preciso da espessura da barreira de proteção. 


\subsection{DOSEPET}

\subsubsection{COMPATIBILIZAÇÃO DO VOLUME DE RADIOFÁRMACO COM DOSE DE RADIAÇÃO POR PACIENTE PET/CT.}

Como já citamos, no Brasil os limites de exposição à radiação são estabelecidos pela CNEN, as dose anuais não podem ultrapassar $1 \mathrm{mSv}$ para indivíduos públicos e $20 \mathrm{mSv}$ para indivíduos ocupacionalmente expostos (CNEN, 2011), porém, as exposições médicas de pacientes não têm limites préestabelecidos, contudo devem ser justificadas ponderando entre os benefícios do diagnóstico ou da terapêutica que venham produzir com os riscos que envolvam a exposição.

A Portaria ํㅜ 453, de 1ํ de junho de 1998 - "Diretrizes de proteção radiológica em radiodiagnóstico médico e odontológico" do Ministério da Saúde estabelece que as instalações e as práticas devem ser planejadas, implantadas e executadas de modo que a magnitude das doses individuais, o número de pessoas expostas e a probabilidade de exposições acidentais sejam tão baixos quanto razoavelmente exequíveis, levando-se em conta fatores sociais e econômicos, além das restrições de dose aplicáveis (Brasil, 1998).

A CNEN discute as doses de radiação e alerta que os riscos de câncer são proporcionais à dose, porém, qualquer valor de dose recebida por uma pessoa, abaixo de $100 \mathrm{mSv}$, não mostra nenhum aumento significativo dos riscos da mesma desenvolver câncer (CNEN, 2016). A tabela a seguir mostra níveis, limites e referências de dose de radiação para uma comparação simplificada: 
Tabela 4 - Comparação entre níveis, limites e referências de dose de radiação.

\begin{tabular}{|c|c|c|}
\hline PARÂMETRO & $\begin{array}{l}\text { VALOR } \\
(\mathrm{mSV})\end{array}$ & OBSERVAÇÕES \\
\hline $\begin{array}{l}\text { Limite anual para público em situação } \\
\text { operacional normal }\end{array}$ & 1 & $\begin{array}{l}\text { Dose acima da radiação natural. Não } \\
\text { inclui aplicações médicas. Ref.: Norma } \\
\text { CNEN-NN-3.01. }\end{array}$ \\
\hline $\begin{array}{l}\text { Aplicações médicas (excluindo } \\
\text { radioterapia) }\end{array}$ & 0,03 a 2,0 & Média anual Ref. UNSCEAR 2008 \\
\hline Radiação natural & 2,4 & $\begin{array}{l}\text { Média anual. Ref. UNSCEAR } 2008 . \\
\text { Algumas regiões apresentam níveis até } \\
5 \text { vezes maiores, por exemplo, a cidade } \\
\text { de Guarapari, ES. }\end{array}$ \\
\hline $\begin{array}{l}\text { Limite anual para indivíduo } \\
\text { ocupacionalmente exposto (trabalhador) }\end{array}$ & 20 & $\begin{array}{l}\text { Média em } 5 \text { anos. Não pode exceder } 50 \\
\text { mSv em um único ano. Ref.: Norma } \\
\text { CNEN-NN-3.01. }\end{array}$ \\
\hline $\begin{array}{l}\text { Nível de ação para evacuação de } \\
\text { população em situações de emergência }\end{array}$ & 50 & $\begin{array}{l}\text { Dose a ser evitada. Monitoração no } \\
\text { local: taxa: } 1 \mathrm{mSv} / \mathrm{h} \text {. Ref.: Norma } \\
\text { CNEN-NN-3.01 PR-006. }\end{array}$ \\
\hline $\begin{array}{l}\text { Limite de dose em situações de } \\
\text { emergência para executar ações para } \\
\text { prevenir o desenvolvimento de situações } \\
\text { catastróficas }\end{array}$ & 100 & $\begin{array}{l}\text { Com exceção das ações para salvar } \\
\text { vidas. Ref.: Norma CNEN-NN-3.01. }\end{array}$ \\
\hline $\begin{array}{l}\text { Referência para aparecimento de efeitos } \\
\text { observáveis }\end{array}$ & 1.000 & $\begin{array}{l}\text { Os efeitos observados podem ser } \\
\text { astenia, náuseas, vômitos. }\end{array}$ \\
\hline $\begin{array}{l}\text { Dose de corpo inteiro mais alta recebida } \\
\text { por uma das vítimas do acidente } \\
\text { radiológico em Goiânia, } 1987\end{array}$ & 8.000 & A vítima faleceu tempos depois. \\
\hline
\end{tabular}

Tabela publicada no site da CNEN em texto que discute as quantidades e riscos das exposições à radiação. $O$ texto foi motivado pela publicação de reportagens na mídia referente ao acidente de Fukushima Dai-ichi. Fonte: (CNEN, 2016).

A média de radiação anual permitida para pacientes está entre 0,03 e 2,0 mSv (tabela 4), esse valor não oferece risco às pessoas que convivem com ele pelo seu caráter esporádico, porém, a equipe de saúde necessita de proteção, pois o somatório das radiações provenientes de vários pacientes e por vários dias pode ser nociva. Isto é, por razões de segurança toda clínica segue rigorosos protocolos de operação que visam a máxima segurança e o mínimo de risco às pessoas. Além disso, devido ao alto custo desses medicamentos, esses protocolos também objetivam o menor esperdício, possível, dos radiofármacos.

A dose injetada em cada paciente leva em conta a meia vida do radiofármaco, o instante de aplicação e a dose inicial de radiação. O App DosePet permite ao farmacêutico simular instantaneamente a relação entre volume e dose do radiofármaco e estabelecer a quantia exata a ser aplicada em cada paciente além de conhecer a quantidade de radiação ainda presente na sala de manipulação devido ao resíduo não utilizado de radiofármaco. 


\subsubsection{CÁLCULO DA DOSE}

A dose a ser aplicada em cada paciente varia com suas características anatômicas e com o órgão que será mapeado. O farmacêutico é o responsável por preparar as doses com o volume correto a ser administrada em cada paciente. $O$ profissional calcula esse volume relacionando os dados iniciais de calibração enviados pelo fabricante e o tempo de meia vida do fármaco com o instante em que as imagens devem ser obtidas. É importante ressaltar que atividade dentro de cada dose varia com o passar do tempo, afinal, a atividade de cada radiofármaco decai com o passar do tempo em função da meia vida de cada elemento.

O volume a ser aplicado em cada paciente $\left(V_{\mathrm{P} 1}\right)$ é uma fração do volume total $\left(\mathrm{V}_{0}\right)$ do radiofármaco disponível estipulado pela proporção da dose necessária ao paciente $\left(D_{P 1}\right)$ com relação à dose total instantânea $(D(t))$ disponível.

$$
V_{P 1}=V_{0} \frac{D_{\mathrm{P} 1}}{D(t)}
$$

\subsubsection{O APP}

No DosePet, são inseridos os dados de calibração do radiofármaco e os dados dos paciente. A partir dessas informações, o App calcula o volume a ser ministrado em cada paciente, além de informar a atividade restante não utilizada em qualquer hora escolhida, como mostra a figura a seguir: 

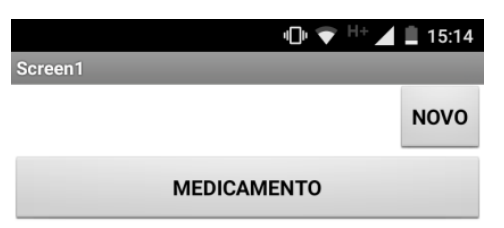

Tipo de medicamento?

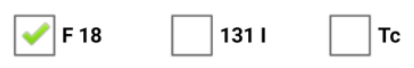

Atividade de Referência (mCi):

85

Volume (ml):

20

Hora da Calibração:

9:50

SALVARE SAIR

\section{$\triangleleft$}

O

(A)
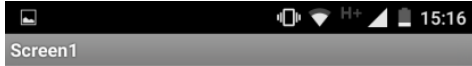

Screen 1

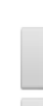

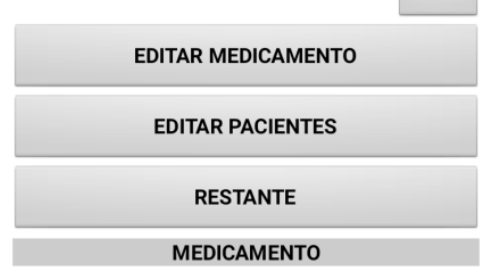

F 18/ 85 mCi/ 9:50/ $20.00 \mathrm{ml}$

\section{LISTA DE PACIENTES}

Paciente 1/ $10 \mathrm{mCi} /$ 10:5/ $2.59 \mathrm{ml}$

Paciente 2/ $11.3 \mathrm{mCi} / 10: 35 /$ $3.53 \mathrm{ml}$

Paciente 3/ $11.9 \mathrm{mCi} / 10: 35$ / $3.72 \mathrm{ml}$

Paciente 4/ 9 mCi/ 11:15/ $3.62 \mathrm{ml}$

Paciente 5/ $8 \mathrm{mCi}$ / 12:25/ $5.01 \mathrm{ml}$

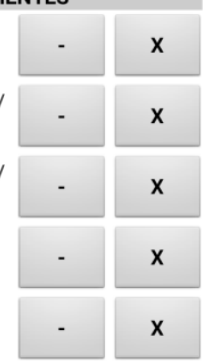

$\square \quad \vdots$

\section{$\triangleleft$}

O

(B)

Figura 10 - Imagens da tela do App DosePet.

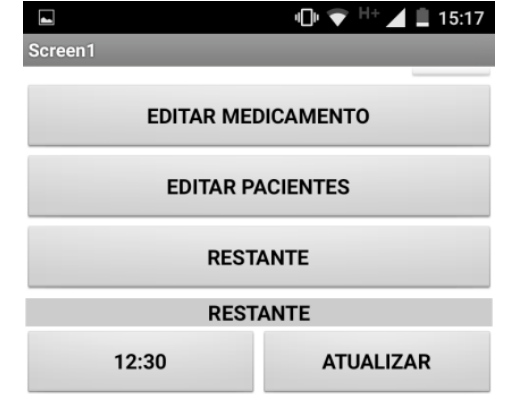

$2.37 \mathrm{mCi} / 1.53 \mathrm{ml}$

MEDICAMENTO

$\mathrm{F} 18 / 85 \mathrm{mCi} / 9: 50 / 20.00 \mathrm{ml}$

LISTA DE PACIENTES

Paciente 1/ $10 \mathrm{mCi} /$ 10:5/ $2.59 \mathrm{ml}$

Paciente 2/ $11.3 \mathrm{mCi} /$ 10:35/ $3.53 \mathrm{ml}$

Paciente 3/ 11.9 mCi/ 10:35/ \begin{tabular}{l} 
Paciente $3.72 \mathrm{ml}$ \\
\hline
\end{tabular}

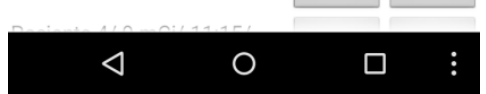

(C)

(A) - Janela para inserção dos parâmetros de calibração do radiofármaco. (B) - Janela para cadastro dos pacientes. (C) - Janela dos resultados e calculo do resto.

O App pode efetuar cálculos para 18F, 131I ou Tc, e também permite excluir ou substituir qualquer paciente ou reeditar qualquer dado - que são ações importantes no planejamento da rotina diária do laboratório e que possibilitam o aproveitamento do radiofármaco mesmo em situações como na falta de algum paciente. 


\subsubsection{DISCUSSÃO}

\section{VALIDAÇÃO DO SOFTWARE}

Como exemplo para discussão do desempenho do DosePet, recalculamos o volume a ser aplicado em 5 pacientes, esse exemplo foi extraído das atas de operação do Scanner PET/CT do HFA. Na tabela, a seguir, temos os dados de calibração do radionuclídeo, a dose e a hora de aplicação de cada paciente. $\mathrm{O}$ mesmo exemplo está representado na figura 9 , apresentada anteriormente.

Tabela 5 - Exemplo de aplicação do DosePet

\begin{tabular}{cccc}
\hline Fármaco & $\begin{array}{c}\text { Hora da } \\
\text { Calibração }\end{array}$ & Dose $(\mathrm{mCi})$ & Volume $(\mathrm{ml})$ \\
\hline FDG & $9: 50$ & 85,0 & 20,00 \\
& & & \\
\hline Paciente & $\begin{array}{c}\text { Hora da } \\
\text { Aplicação }\end{array}$ & Dose $(\mathrm{mCi})$ & $\begin{array}{c}\text { Volume } \\
\text { DosePet }\end{array}$ \\
\hline Paciente 1 & $10: 05$ & 10,0 & 2,59 \\
Paciente 2 & $10: 35$ & 11,3 & 3,53 \\
Paciente 3 & $10: 35$ & 11,9 & 3,72 \\
Paciente 4 & $11: 15$ & 9,0 & 3,62 \\
Paciente 5 & $12: 25$ & 8,0 & 5,01
\end{tabular}

De acordo com o exemplo, a diferença entre o volume total aplicado (18, 47 $\mathrm{ml})$ e o volume de fármaco $(20 \mathrm{ml})$ não foi utilizada, logo o restante se encontra-se no laboratório e ainda com uma dose ativa. Além de calcular com precisão (de $100 \%)$ o volume a ser injetado em cada paciente em função do horário, com DosePet é possível verificar que às $12: 30$ nos $1,53 \mathrm{ml}$ que restaram das aplicações há $2,37 \mathrm{mCi}$, informação essencial para as pessoas que precisam transitar nas dependências internas do laboratório - como está ilustrado na figura 9.

Seguindo com o exemplo, vamos supor que o paciente 3 falte e por isso essa aplicação não seja realizada, com o DosePet essa situação também é facilmente simulada. Como mostra a figura a seguir: 


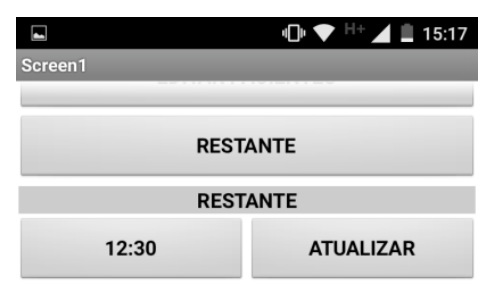

$8.13 \mathrm{mCi} / 5.25 \mathrm{ml}$ MEDICAMENTO F 18/ $85 \mathrm{mCi} / 9: 50 / 20.00 \mathrm{ml}$ LISTA DE PACIENTES Paciente 1/ $10 \mathrm{mCi} / 10: 5 /$ $2.59 \mathrm{ml}$

Paciente 2/ $11.3 \mathrm{mCi} / 10: 35 /$ $3.53 \mathrm{ml}$

Paciente $3 / 11.9 \mathrm{mCi} /$ 10:35 $3.72 \mathrm{ml}$

Paciente 4/ 9 mCi/ 11:15/ $3.62 \mathrm{ml}$

Paciente 5/ 8 mCi/ 12:25/ $5.01 \mathrm{ml}$

$\triangleleft$

$\square$

(A)

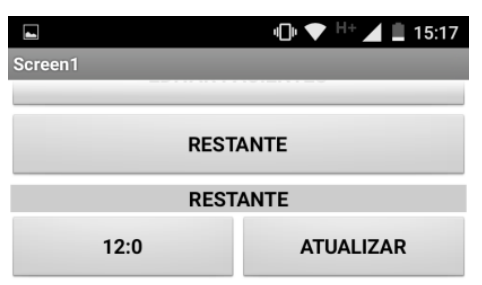

$9.82 \mathrm{mCi} / 5.25 \mathrm{ml}$ MEDICAMENTO

F 18/ $85 \mathrm{mCi} /$ 9:50/ $20.00 \mathrm{ml}$ LISTA DE PACIENTES

Paciente 1/ $10 \mathrm{mCi} / 10: 5 /$ $2.59 \mathrm{~m}$

Paciente 2/ $11.3 \mathrm{mCi} /$ 10:35/ $3.53 \mathrm{ml}$

Paciente 3/ $11.9 \mathrm{mCi} / 10: 35$ $3.72 \mathrm{ml}$

Paciente 4/ $9 \mathrm{mCi}$ / 11:15/ $3.62 \mathrm{ml}$

Paciente 5/ $8 \mathrm{mCi} / 12: 25 /$ $5.01 \mathrm{ml}$

\section{$\triangleleft$}

Figura 11 - Imagens da tela do App DosePet.

Figura 11 - Imagens da tela do App DosePet.

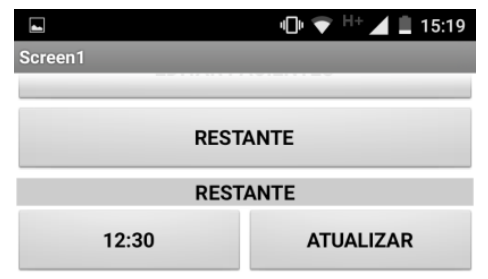

$0.12 \mathrm{mCi} / 0.08 \mathrm{ml}$

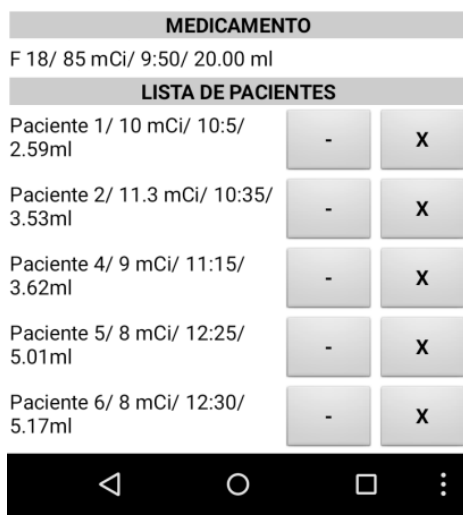

(C)

(A) - Após suspender o paciente 3 clicando no botão (-), o restante as 12:30 é de 8, 13 mCi em 5, 25 $\mathrm{ml}$. (B) - Se alterarmos o horário do resíduo, verificamos que sem o paciente 3 as 12:00 o resto é de 9, $82 \mathrm{mCi}$ em 5, $25 \mathrm{ml}$. (C) - Ao acrescentar o paciente 6 a lista e o DosePet atualiza o volume e a dose de radiação do resíduo.

Com o paciente 3 suspenso, teremos $5,25 \mathrm{ml}$ de radiofármaco sobrando. A utilização do DosePet permite verificar, por exemplo, que às 12:00 sua atividade será de $9,82 \mathrm{mCi}$ ou que às $12: 30$ será de $8,13 \mathrm{mCi}$. Em outras palavras, o DosePet permite verificar a atividade do restante em qualquer horário necessário. Esse tipo de informação possibilita que outro paciente seja atendido, minimizando o desperdício. E, como representado na figura 10 (C), se acrescentarmos o paciente 6 no lugar do paciente $3 \mathrm{com}$ uma dose de $8 \mathrm{mCi}$, às 12:30 restarão apenas $0,12 \mathrm{mCi}$ em $0,08 \mathrm{ml}$ do radiofármaco. 


\section{CONCLUSÃO}

O objetivo inicial desse trabalho foi desenvolver uma ferramenta computacional, o BlindPet, para Medicina Nuclear, que auxiliasse o cálculo da espessura das barreiras de contenção radioativa das instalações que executam a técnica PET/CT. Ao longo do processo de pesquisa conseguimos compreender a metodologia de produção de software $e$ as peculiaridades da prática dos profissionais que atuam com PET/CT, isso nos permitiu propor e construir o App DosePet, que calcula o volume de medicamento necessário para que cada paciente receba a dose exata de medicação.

O trabalho resultou em dois registros de software, conforme anexo, que contribuirão para que os profissionais envolvidos diretamente com a técnica de obtenção de imagens com PET/CT, ou ainda, no ensino ou no treinamento das metodologias de blindagem e de dosimetria a profissionais e estudantes da área.

Considerando o crescimento projetado para instalações que utilizam a técnica de PET/CT, o design apropriado para os centros de imagem continuará a ser um dos mais significativos desafios de proteção de radiação enfrentados pelos físicos médicos em todo o mundo (Pasciaka, 2012). Tendo em vista esse cenário, acreditamos que o BlindPet pode contribuir com o cálculo de blindagens devido à velocidade dos cálculos, sua praticidade e principalmente à precisão, além de também possibilitar adequações em casos de modificações estruturais.

Na maioria dos laboratórios de radio farmácia, as doses de radiofármacos são calculadas e separadas manualmente. A utilização de um software para o cálculo do volume exato de cada dose minimiza o tempo de exposição dos indivíduos ocupacionalmente expostos e elimina possíveis erros de acurácia. O DosePet contribuirá para o cálculo mais preciso e rápido do volume de medicamento necessário para cada paciente. Assim, considerando o crescimento do emprego da técnica $\mathrm{PET} / \mathrm{CT}$, esse App também auxiliará na redução da exposição dos indivíduos ocupacionalmente expostos, na minimização de custos e na otimização de rotinas de exames.

Para estudos futuros foram identificadas práticas que os profissionais adotam ou gostariam de adotar, e que supostamente reduziriam o tempo de exposição da equipe de trabalho aos radiofármacos e aumentariam os níveis de segurança nos 
laboratórios PET/CT, acreditamos que os aplicativos podem contribuir na coleta dados e análise dessas práticas.

Outro aspecto importante, é que os Apps certamente podem evoluir, e fornecer melhores respostas aos usuários e também podem ser adaptados para implantação em ambientes que necessitem de soluções semelhantes. 


\section{REFERÊNCIAS BIBLIOGRÁFICAS}

1. Antic V, Stankovic K, Vujisic M, et al. Comparison of various methods for designing the shielding from ionising radiation at pet-ct installations. Radiation Protection Dosimetry, Vol. 154, № 2, p. 245-249, 2013.

2. Arce $P$, Lagares $\mathrm{Jl}$, Perez-Astudillo $\mathrm{D}$, et al. Optimization of an external beam radiotherapy treatment using GAMOS/Geant4World Congress on Medical Physics and Biomedical Engineering. IFMBE Proceedings Vol. 25/1, Setembro de 2009.

3. Beck, K. Programação Extrema Explicada. Bookman. 1999.

4. Brasil. Ministério da Saúde. Secretaria de Vigilância Sanitária. Diretrizes de proteção radiológica em radiodiagnóstico médico e odontológico. Portaria № 453, de $1^{\circ}$ de junho de 1998.

5. Brix G, Lechel U, Glatting G, et al. Radiation exposure of patients undergoing whole-body dual-modality 18F-FDG PET/CT examinations. J Nucl Med. 46(4):608-13, Abril de 2005

6. CNEN. Diretrizes Básicas de Proteção Radiológica. CNEN NN-3.01:2011 Setembro de 2011.

7. CNEN. Entendendo um pouco sobre as doses de radiação e a sua unidade de medida Sievert, 2016.2 Disponível em: <http://www.cnen.gov.br/noticias/documentos/entendendo_radiacao.pdf>, acessado em 06 de abril de 2016.

8. Correia PD, Granzotti CRF, Santos YS, et al. Caracterização de uma blindagem de chumbo protetora de mamas para redução de dose em exames de Tomografia Computadorizada. XVIII Congresso Brasileiro de Física Médica, Agosto de 2013.

9. Devine CE, Mawlawi O. Radiation safety with positron emission tomography and computed tomography. Semin Ultrasound CT MR.31(1):39-45. doi: 10.1053/j.sult.2009.09.005, Fevereiro de 2010.

10. Doot RK, Thompson T, Greer BE, et al. QIN. Early experiences in establishing a regional quantitative imaging network for PET/CT clinical trials. Magn Reson Imaging. 30(9): 1291-1300, Novembro de 2012.

11. Fog LS, Cormack J. Mathematical modeling of the radiation dose received from photons passing over and through shielding walls in a PET/CT suite. Health Phys.99(6):769-79. doi: 10.1097/HP.0b013e3181e47a39, Dezembro de 2010.

12. Harper PV, Beck R, Charleston D, Lathrop KA. Optimization of a scanning method using technetium-99m. Nucleonics. 1964.

13. Henríquez FC, Castrillón SV. Impact of a PET/CT Facility in its Community 
Environment. Revista Española de Salud Pública. Vol.85 №3 Madrid, Maio/ Junho de 2011.

14. Krabbe CA, Balink $\mathrm{H}$, Roodenburg JL, Dol J, Visscher JG. Performance of 18F-FDG PET/contrast-enhanced CT in the staging of squamous cell carcinoma of the oral cavity and oropharynx. Int J Oral Maxillofac Surg.40: 1263-1270. 2011.

15. Madsen MT, Anderson JA, Halama JR, et al. AAPM Task Group 108: PET and PET/CT Shielding Requirements. Medical Physics, Vol. 33, N 1, Janeiro de 2006.

16. Marsh MB, Peters C, Rawluk N, Schreiner LJ. Investigation of photon shielding property changes in curing high density concrete. Health Phys, 105(4):318-25, Outubro de 2013.

17. MIT App Inventor, Explore MIT App Inventor, 2015. Disponível em: $<$ http://Appinventor.mit.edu/explore>, acessado em 20 de janeiro de 2016.

18. Mourato FA, Moser LDN, Mattos SS. Sistema interativo em ambiente móvel para o diagnóstico diferencial de cardiopatias congênitas. J. Health Inform. 5(4):127-31, Outubro/ Dezembro de 2013.

19. NBPF. Basic of PET-CT. Disponível em: <http://www.med.harvard.edu/JPNM/chetan/petct/petct.html>, acessado em 25 de janeiro de 2016.

20. Nestle U, Kremp S, Grosu A-L. Practical integration of [18F]-FDG-PET and PET-CT in the planning of radiotherapy for non-small cell lung cancer (NSCLC): the technical basis, ICRU-target volumes, problems, perspectives. Radiother Oncol, 81:209-25, 2006.

21. Nye JA, Dubose M, Votaw JR. A comparison of AAPM TG-108 PET/CT shielding recommendations to measurements in an oncology cente. Medical Physics, Vol. 36, N 11, November de 2009.

22. Pasciaka AS, Jones AK. PShield: An exact three-dimensional numerical solution for determining optimal shielding designs for PET/CT facilities. Medical Physics, Vol. 39, №6, Junho de 2012.

23. Peet DJ, Morton $R$, Hussein $M$, et al. Radiation protection in fixed PET/CT facilities-design and operation. Br J Radiol. 85(1013): 643-646, Maio de 2012.

24. Robilotta CC. A tomografia por emissão de pósitrons: uma nova modalidade na medicina nuclear brasileira. Revista Panamericana de Salud Pública. 2006.

25. Snyder WS, Fisher HL Jr, Ford MR, Warner GG. "MIRD Pamplet 5: Estimates of absrobed fractions for monenergetic photon sources uniformly distributed in various organs of a heterogeneous phantom," J. Nucl. Med., Suppl. 10 
Supplement 3, 1969.

26. Workman RB Jr, Coleman RE. PET/CT - Essentials for Clinical Practice Fundamentals of PET and PET/CT Imaging. 2006.

27. Xie B, Shabir I, Abelson H. Measuring the Usability and Capability of App Inventor to Create Mobile Applications. 2015 ACM SIGPLAN Conference on Systems, Programming, Languages and Applications: Software for Humanity (SPLASH), Outubro de 2015.

28. Yamaga LYI, Marcelo LC, Jairo W, et al. Valor diagnóstico da tomografia por emissão de pósitrons / tomografia computadorizada (PET-CT) com flúor-18 fluordeoxiglicose (FDG-18F) em pacientes com carcinoma diferenciado da tireoide, níveis séricos de tireoglobulina elevados e pesquisa de corpo inteiro com iodo negativa. Arquivos Brasileiros de Endocrinologia \& Metabologia. Vol. 51. № 4. São Paulo, Junho de 2007. 


\title{
Apresentação do aplicativo DosedPet para uso em Medicina Nuclear - Cálculo do volume de medicamento necessário para paciente de PETCT.
}

\author{
Primeiro A. Autor ${ }^{1}$, Segundo B. Co-autor ${ }^{2}$, Último C. Co-autor ${ }^{3}$ \\ Pedro Augusto do Nascimento ${ }^{1}$, Araken dos S. Werneck Rodrigues ${ }^{2}$ \\ ${ }^{1}$ Programa de Pós Graduação em Ciências e Tecnologias em Saúde, Faculdade Ceilândia- \\ Universidade de Brasília - UnB, Mestrando, Brasília, Brasil \\ ${ }^{2}$ Programa de Pós Graduação em Ciências e Tecnologias em Saúde, Faculdade Ceilândia- \\ Universidade de Brasília - UnB, Professor, Brasília, Brasil
}

\begin{abstract}
Resumo
Nesse trabalho, apresentamos o Aplicativo (APP) DosePet que tem por objetivo o cálculo do volume por meio da atividade das doses administradas a pacientes de PET/CT. O software foi projetado utilizando a ferramenta Web MIT App Inventor2 para plataforma Android. O aplicativo permite avaliar a quantidade de radiação ainda existente nas instalações após as aplicações, aumentando a segurança e diminuindo as exposições, além de possibilitar maior eficiência no aproveitamento do radiofármaco.
\end{abstract}

Palavras-chaves: Dose PET/CT, física médica, Aplicativo.

\begin{abstract}
This paper presents the application (APP) DosePet that calculates the amount of medicament for PET / CT in patients according to the predetermined radiation dose. The software has been designed using the web MIT App Inventor2 tool for Android platform. The application allows the workers to simulate the amount of radiation still existing in the premises after the applications, increasing security and reducing exposures, and enable greater efficiency in the use of the radiopharmaceutical.
\end{abstract}

Keywords: dose PET / CT, medical physics, Application.

1. Introdução

A técnica PET/CT (Pósitron Emission Tomography/Computed Ttomography) é um exame capaz de obter imagens da anatomia e da fisiologia humana por meio da identificação de radiotraçadores da atividade metabólica injetados em pacientes, sendo atualmente uma ferramenta recomendada para o diagnóstico/ acompanhamento de diversos tipos de cânceres ${ }^{1}$. Entretanto esse procedimento expõe pacientes e trabalhadores à radiação, o que gera interesse em estabelecer protocolos que possam minimizar a exposição sem prejuízo do diagnóstico².

A técnica de PET usa a detecção de fótons provenientes da aniquilação de pósitron-elétron para obter os dados necessários para a construção de imagens. $O$ decaimento espontâneo em certos radionuclídeos converte um próton em um nêutron, um neutrino e um pósitron. $O$ pósitron segue até colidir com um elétron e, como elétron e pósitron são antipartículas, a colisão entre eles resulta em aniquilação mútua, produzindo dois fótons em sentidos opostos e com $511 \mathrm{keV}$ cada, como esquematizado na figura 1 a seguir.

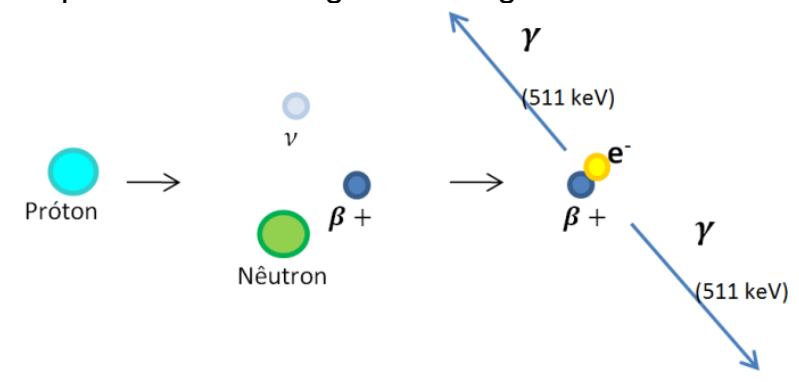

Figura 1 - Decaimento $\beta+$ e aniquilação pósitron elétron. 
Radioisótopos emissores de pósitrons utilizados em imagens médicas geralmente têm meias-vidas curtas, como mostra tabela 1 , a seguir, e consequentemente, muitos deles, como O-15, N-13, e C-11, têm de ser produzidos com um cíclotron no local do exame, a fim de dispor de quantidades clinicamente úteis ${ }^{3}$.

Tabela 1 - Propriedades físicas dos radionuclídeos mais utilizados.

\begin{tabular}{llc}
\hline Radionuclídeo & Meia-vida & $\begin{array}{c}\text { Tipo de } \\
\text { decaimento }\end{array}$ \\
\hline $11 \mathrm{C}$ & $20,4 \mathrm{~min}$ & $\beta+$ \\
$13 \mathrm{~N}$ & $10,0 \mathrm{~min}$ & $\beta+$ \\
$15 \mathrm{O}$ & $2,0 \mathrm{~min}$ & $\beta+$ \\
$18 \mathrm{~F}$ & $109,8 \mathrm{~min}$ & $\beta+, \mathrm{EC}$ \\
$64 \mathrm{Cu}$ & $12,7 \mathrm{~h}$ & $\beta-, \beta+, \mathrm{EC}$ \\
$68 \mathrm{Ga}$ & $68,3 \mathrm{~min}$ & $\beta+, \mathrm{EC}$ \\
$82 \mathrm{Rb}$ & $76 \mathrm{~s}$ & $\beta+, \mathrm{EC}$ \\
$124 \mathrm{I}$ & $4,2 \mathrm{~d}$ & $\beta+, \mathrm{EC}$
\end{tabular}

Atualmente, o radionuclídeo mais utilizado na técnica de $\mathrm{PET} / \mathrm{CT}$ é o $18 \mathrm{~F}$, marcando a fluordeoxiglicose (FDG), um análogo da glicose que é consumido por células ativas, de tal maneira que sua presença indica função metabólica tecidual. Os quase 110 minutos de meia-vida do $18 \mathrm{~F}$ permitem que a FDG marcada seja transportada a locais de exame razoavelmente afastados do centro de produção (em torno de $100 \mathrm{~km}$ por transporte terrestre), de modo que a PET realizada com FDG é dominante, com aplicações principalmente em oncologia e, em menor extensão, em neurologia, psiquiatria e cardiologia ${ }^{4}$.

No Brasil, a CNEN (Comissão Nacional de Energia Nuclear) estabelece os limites de dose para pacientes, para indivíduos ocupacionalmente expostos e para o público em geral. A dose de radiação absorvida por um indivíduo é medida no sistema internacional em joule por quilograma $(\mathrm{J} / \mathrm{kg})$, denominada Sievert (Sv). O limite de dose anual não pode ultrapassar $1 \mathrm{mSv}$ para indivíduos públicos e $20 \mathrm{mSv}$ para indivíduos ocupacionalmente expostos $^{5}$. A dose de radiação injetada no paciente não é suficiente para causar danos nele ou nas pessoas que convivem com ele, contudo a equipe de saúde que realiza esses exames, indivíduos ocupacionalmente expostos, necessita de proteção, pois o somatório das radiações provenientes de vários pacientes e por vários dias pode ser nociva.

A Portaria no 453, de 1ำ de junho de 1998 "Diretrizes de Proteção Radiológica em Radiodiagnóstico Médico e Odontológico" do Ministério da Saúde estabelece que as instalações e as práticas devem ser planejadas, implantadas e executadas de modo que a magnitude das doses individuais, o número de pessoas expostas e a probabilidade de exposições acidentais sejam tão baixos quanto razoavelmente exequíveis, levando-se em conta fatores sociais e econômicos, além das restrições de dose aplicáveis ${ }^{6}$.

Por razões de segurança e devido ao alto custo, os laboratórios seguem rigorosos protocolos de operação visando à máxima segurança e ao mínimo de risco e de desperdício. Nesse contexto, o App (Aplicativo) DosePet foi criado para auxiliar o farmacêutico no cálculo do volume de medicamento necessário para que cada paciente receba a dose exata de medicação. Esse aplicativo é importante, pois ele permite simular instantaneamente a relação entre volume e dose do radiofármaco.

\section{Materiais e Métodos}

O DosePet foi projetado para plataforma Android, por ser amplamente utilizada, pela possibilidade de compartilhamento por meio da Google Play Store e por não haver a necessidade de licença de desenvolvedor ${ }^{7}$. A programação foi desenvolvida utilizando a ferramenta Web MIT App Inventor2.

O DosePet ainda está em processo de registro. Os leitores interessados no aplicativo podem entrar em contato com os autores através do e-mail pedroan88@gmail.com.

\subsection{Cálculo Da Dose}

$A=\frac{d N}{d t}$

A atividade é a grandeza definida por

onde $\mathrm{dN}$ é o valor esperado do número de transições nucleares espontâneas daquele estado de energia no intervalo de tempo dt. A unidade no sistema internacional é denominada Becquerel (Bq), contudo comercialmente a unidade mais utilizada é Curie $(\mathrm{Ci})$, sendo $1 \mathrm{MBq}$ $=37,012 \mathrm{mCi}$.

A atividade de cada radiofármaco decai com o passar do tempo em função da meia vida de cada elemento. Se conhecermos a atividade de certo radionuclídeo em um determinado instante, é possível calcular a atividade em qualquer tempo posterior ou anterior.

A dose a ser aplicada em cada paciente varia com suas características anatômicas e com 
a parte do corpo que será mapeada. O farmacêutico é o responsável por preparar as doses com o volume correto a ser aplicado em cada paciente. $O$ profissional calcula esse volume relacionando os dados iniciais de calibração enviados pelo fabricante e o tempo de meia vida do fármaco com o instante em que as imagens devem ser obtidas. É importante ressaltar que atividade dentro de cada dose varia com o passar do tempo, por isso o instante em que será aplicado esse medicamento precisa ser levado em conta.

O volume a ser aplicado em cada paciente $\left(\mathrm{V}_{\mathrm{p} 1}\right)$ é uma fração do volume total $\left(\mathrm{V}_{0}\right)$ do radiofármaco disponível estipulado pela proporção da dose necessária ao paciente $\left(D_{p 1}\right)$ com relação à dose total instantânea $(\mathrm{D}(\mathrm{t}))$ disponível.

$V_{P 1}=V_{0} \frac{D_{p 1}}{D(t)}$

(2)

\subsection{Aplicativo}

No aplicativo DosePet, serão inseridos os dados de calibração do radiofármaco e os dados do paciente. A partir dessas informações, o aplicativo calcula o volume a ser ministrado em cada paciente, além de informar a atividade restante não utilizada em qualquer hora escolhida, como mostra a figura 2 a seguir:

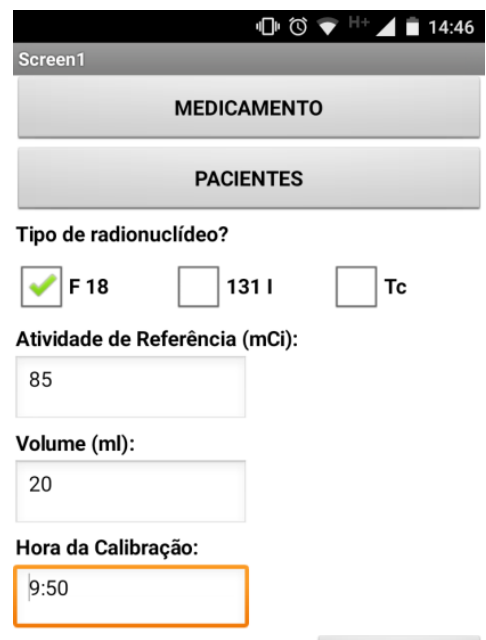

SALVAR E SAIR

\section{$\triangleleft$}

$\mathrm{O}$

$\square$

Figura 2 (A) - Janela para inserção dos parâmetros de calibração do radiofármaco.

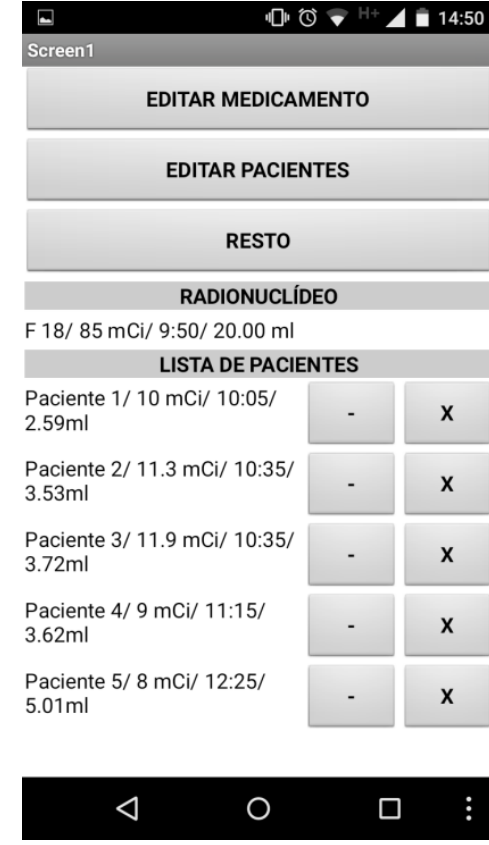

Figura 2 (B) - Janela para cadastro dos pacientes.

\begin{tabular}{|c|c|}
\hline 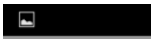 & $\nabla^{H+} \boldsymbol{\Delta}$ \\
\hline Screen 1 & \\
\hline & MENTO \\
\hline & NTES \\
\hline & \\
\hline & \\
\hline $12: 30$ & ATUALIZAR \\
\hline
\end{tabular}

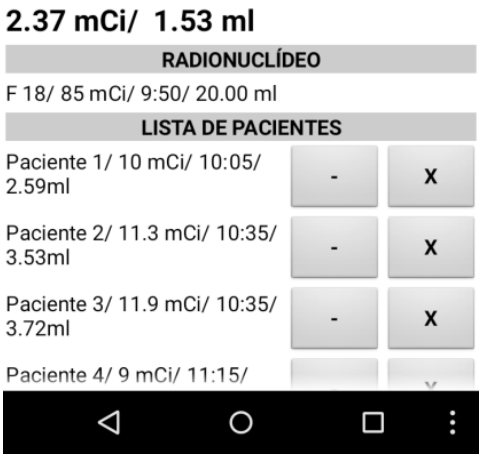

Figura 2 (C) - Janela dos resultados e calculo do resto.

O aplicativo pode efetuar cálculos para 18F, 131I ou Tc, e também permite excluir ou substituir qualquer paciente ou reeditar qualquer dado - que são ações importantes no planejamento da rotina diária do laboratório e que possibilitam o aproveitamento do radiofármaco mesmo em situações como na falta de algum paciente.

\section{Resultados}

Como exemplo para análise do desempenho do DosePet, recalculamos 0 volume a ser aplicado em 5 pacientes. Na tabela 2 , a seguir, temos os dados de calibração do 


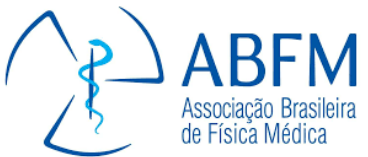

radionuclídeo, a dose e a hora de aplicação de cada paciente. $\bigcirc$ mesmo exemplo está representado na figura 1.

Tabela 2 - Exemplo de aplicação do DosePet

\begin{tabular}{lccc}
\hline Fármaco & Hora & Dose $(\mathrm{mCi})$ & Volume $(\mathrm{ml})$ \\
\hline FDG & $9: 50$ & 85,0 & 20,00 \\
\hline Paciente & Hora & Dose $(\mathrm{mCi})$ & $\begin{array}{l}\text { Volume } \\
\text { DosePet }\end{array}$ \\
\hline Paciente 1 & $10: 05$ & 10,0 & 2,59 \\
Paciente 2 & $10: 35$ & 11,3 & 3,53 \\
Paciente 3 & $10: 35$ & 11,9 & 3,72 \\
Paciente 4 & $11: 15$ & 9,0 & 3,62 \\
Paciente 5 & $12: 25$ & 8,0 & 5,01
\end{tabular}

De acordo com o exemplo, a diferença entre o volume total aplicado $(18,47 \mathrm{ml})$ e o volume de fármaco $(20 \mathrm{ml})$ não foi utilizada, logo esse resíduo se encontra no laboratório e ainda com uma dose ativa. Com o DosePet verificamos que às $12: 30$ os $1,53 \mathrm{ml}$ que restaram das aplicações ainda terá $2,37 \mathrm{mCi}$, informação essencial para as pessoas que precisam transitar nas dependências internas do laboratório.

Seguindo com o exemplo, vamos supor que o paciente 3 falte e por isso essa aplicação não seja realizada, com o DosePet essa situação também é facilmente simulada. Como mostra a figura 3 a seguir:

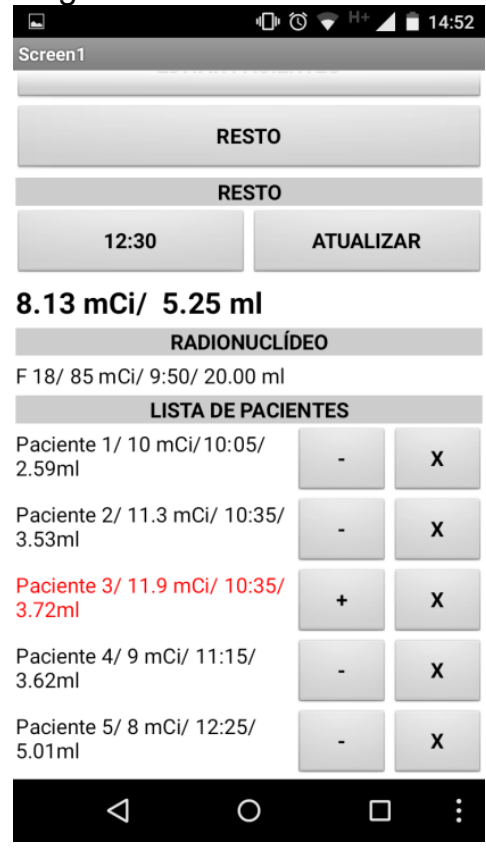

Figura 3 (A) - Após suspender o paciente 3 clicando no botão

(-), o resto as 12:30 é de $8,13 \mathrm{mCi} \mathrm{em} \mathrm{5,25} \mathrm{ml.}$
XXI Congresso Brasileiro de Física Médica 24 a 27 de Agosto de 2016 Florianópolis

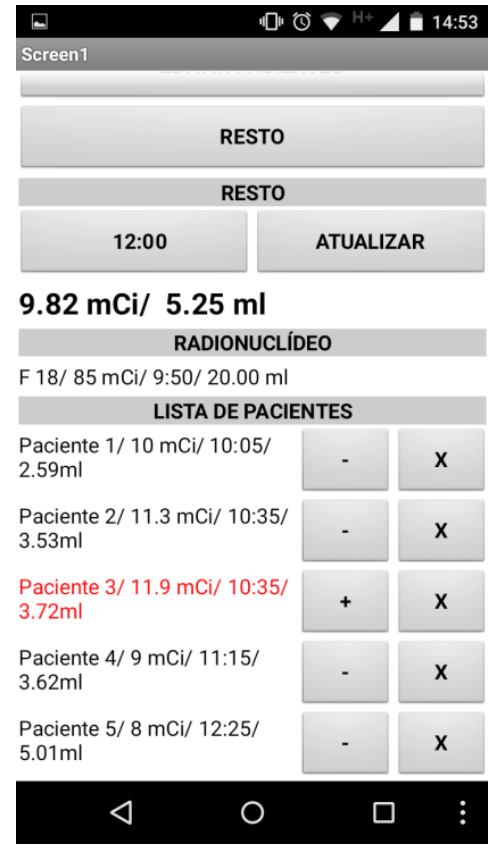

Figura 3 (B) - Sem o paciente 3 as 12:00 o resto é de 9,82 $\mathrm{mCi}$ em $5,25 \mathrm{ml}$.
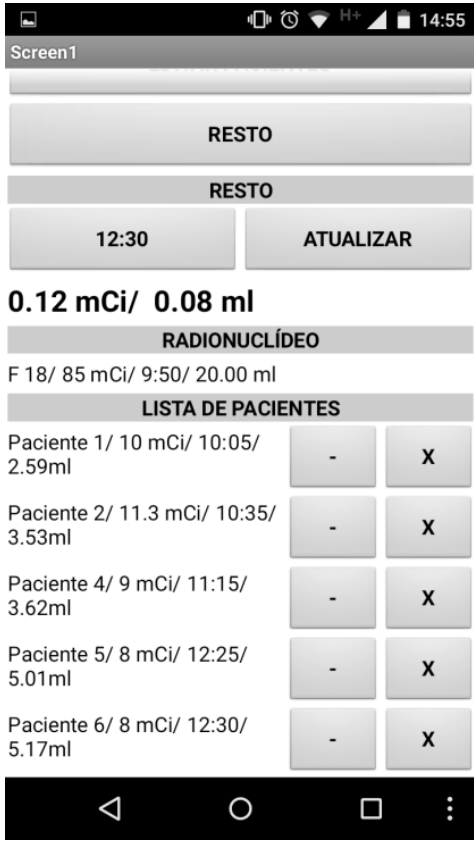

Figura 3 (C) - Ao acrescentar o paciente 6 a lista e o DosePet atualiza o volume e a dose de radiação do resto.

Com o paciente 3 suspenso, teremos $5,25 \mathrm{ml}$ de radiofármaco sobrando. A utilização do DosePet permite verificar, por exemplo, que às $12: 00$ sua atividade será de $9,82 \mathrm{mCi}$ ou que às $12: 30$ será de $8,13 \mathrm{mCi}$. Em outras palavras, - DosePet permite verificar a atividade do resíduo em qualquer horário necessário. Esse tipo de informação possibilita que outro paciente seja atendido, minimizando o desperdício. E, como representado na figura 3 (C), se acrescentarmos 0 paciente 6 no lugar do 
paciente 3 com uma dose de $8 \mathrm{mCi}$, às $12: 30$ restarão apenas $0,12 \mathrm{mCi}$ em $0,08 \mathrm{ml}$ do radiofármaco.

\section{Discussão}

Na maioria dos laboratórios, as doses de radiofármacos são calculadas e separadas manualmente. A utilização de um software para o cálculo do volume exato de cada dose minimiza - tempo de exposição dos indivíduos ocupacionalmente expostos e elimina possíveis erros de acurácia.

O DosePet é um software de MN Medicina Nuclear, PET, PET/CT e PET/MR que otimiza a prática laboratorial e melhora a segurança dos trabalhadores, pacientes e do público em geral.

\section{Conclusão}

O presente trabalho irá contribuir com o cálculo mais preciso e rápido do volume de medicamento necessário para cada paciente. Assim, considerando o crescimento do emprego da técnica PET/CT, esse aplicativo também auxiliará na redução da exposição dos indivíduos ocupacionalmente expostos, na minimização de custos e na otimização de rotinas de exames. Trata-se, portanto, de uma ferramenta útil aos profissionais que trabalham em laboratórios $\mathrm{PET} / \mathrm{CT}$, e pode ainda ser uma ferramenta vantajosa em atividades de treinamento e de ensino da metodologia aos profissionais e aos estudantes da área.

\section{Referências}

1. José Soares Junior; Roberto Porto Fonseca; Juliano Julio Cerci; Carlos Alberto Buchpiguel; Marcelo Livorsi da Cunha; Marcelo Mamed; Sérgio Altino de Almeida. Lista de recomendações do Exame PET/CT com18F-FDG em Oncologia. Consenso entre a Sociedade Brasileira de Cancerologia e a Sociedade Brasileira de Biologia, Medicina Nuclear e Imagem Molecular. Radiol Bras vol.43 no.4 São Paulo July/Aug. 2010.

2. Solange Amorim Nogueira; Henrique Manoel Lederman Jairo Wagne; Lilian Yuri Yamaga; Marcelo Livorsi da Cunha; Marcelo Buarque de Gusmão Funari. Estudo comparativo da qualidade de imagem dos modos de aquisição da PET: validação de um protocolo para reduzir a dose de radiação. Radiol Bras vol.42 no.2 São Paulo Mar./Apr. 2009

3. Madsen M T et al, AAPM Task Group 108: PET and PET/CT Shielding Requirements. Medical Physics, Vol. 33, $\mathrm{N}^{\circ}$ 1, Janeiro 2006.

4. Robilotta CC. A tomografia por emissão de pósitrons: uma nova modalidade na medicina nuclear brasileira. Rev Panam Salud Publica. 2006; 20(2/3):134-42

5. CNEN. Diretrizes Básicas de Proteção Radiológica . CNEN NN-3.01:2011 Setembro/2011.

6. Brasil. Ministério da Saúde. Secretaria de Vigilância Sanitária. Diretrizes de proteção radiológica em radiodiagnóstico médico e odontológico. Portaria no 453 , de $1^{\circ}$ de junho de 1998.

7. MIT App Inventor, Explore MIT App Inventor, 2015. Disponível em: <http://appinventor.mit.edu/explore>, acessado em 20 de janeiro de 2016.

\section{Contato}

Pedro Augusto do Nascimento

Campus Universitário, Centro Metropolitano 1, Conjunto A Prédio Unidade de Ensino e Docência (UED), 1 ํ piso.

Ceilândia Sul (Ceilândia) - Brasília-DF

CEP: $72220-900$

E-mail: pedroan88@gmail.com 
Anexo 2 - normas para publicação - ARTIGO 1

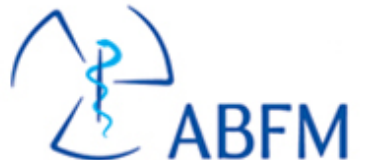
Associaçăo Brasileira de Fisica Médica

\section{Revista Brasileira de Física Médica}

ISSN 1984-9001

Submissão de Trabalhos

Existem duas formas de submissão de trabalhos para o Congresso Brasileiro de Física Médica:

- resumo expandido de 02 (duas) páginas;

- artigo completo de 04 (quatro) páginas.

Todos os trabalhos aprovados e apresentados serão publicados nos anais do evento.

Os melhores trabalhos apresentados no congresso, em formato completo, serão publicados na Revista Brasileira de Física Médica (RBFM), após avaliação do Comitê Editorial da Revista. Não serão publicados resumos expandidos na Revista Brasileira de Física Médica.

A submissão dos trabalhos NÃO TERÁ AS DATAS PRORROGADAS.

Cada trabalho apresentado será revisado por dois avaliadores. As respostas sobre o aceite serão enviadas de acordo com a ordem de chegada dos trabalhos, com prazos fixados no calendário. Se você precisa do aceite do seu trabalho para pedir apoio para alguma instituição de fomento, faça a submissão com a devida antecedência.

TODOS OS AUTORES E CO-AUTORES PRECISAM SE CADASTRAR NO SITE, INDEPENDENTEMENTE DE PARTICIPAREM OU NÃO DO EVENTO.

Procedimento para Submissão de Trabalhos 
1. Antes de iniciar a submissão de trabalhos, você e os demais autores devem estar cadastrados no sistema. Pelo menos um dos autores deve pagar a taxa de inscrição no evento para que o trabalho aceito seja apresentado/publicado.

2. Use o botão Crie / Acesse sua conta para cadastrar todos os autores.

3. Faça o download do modelo Word de sua preferência (resumo expandido ou do artigo completo).

4. Cada campo do trabalho deve ser preenchido, preservando a formatação do modelo. NÃO ALTERE A FORMATAÇÃO.

5. Salve o documento que contém o seu TRABALHO em seu computador.

6. Faça seu login no sistema e clique no botão TRABALHOS.

7. Clique em SUBMETER UM NOVO TRABALHO.

8. Escolha o tipo de apresentação dentre as opções fornecidas: ORAL ou PÔSTER.

9. Escolha a área temática que melhor se adapta à sua contribuição.

10. Digite o título de seu trabalho no campo TíTULO.

11. Coloque o texto do resumo de seu trabalho na caixa RESUMO. Lembre-se que neste campo deve ser colocado apenas o texto do resumo de 300 palavras, sem constar autor, título, tema e tipo de apresentação. Um contador no rodapé da caixa irá mostrar o espaço disponível restante para o texto do resumo do trabalho.

12. Para enviar seu trabalho clique no botão UPLOAD. Escolha o lugar no qual você salvou o seu TRABALHO no computador e faça o upload do arquivo. SALVE o trabalho submetido.

13. Clique em AUTORES para escolher os co-autores deste resumo, que devem estar cadastrados no sistema. Após a escolha, SALVE as informações.

14. Escolha na lista o trabalho recentemente submetido. SALVE as informações.

15. Você pode verificar todas as informações apresentadas ao clicar no título do trabalho na lista de trabalhos.

16. Durante o período de submissão seu trabalho pode modificado ou excluído.

17. Ao término do período de submissão NÃO SERÃO PERMITIDAS ALTERAÇÕES nos trabalhos. 
Anexo 3 - ARTIGO 2

Comprovante de submissão e artigo 2

American Association of Physicists in Medicine

Journal of Applied Clinical Medical Physics

$\begin{array}{llrlrl}\text { HOME } & \text { ABOUT } & \text { USER HOME } & \text { SEARCH } & \text { CURRENT } & \text { ARCHIVES } \\ \text { ANNOUNCEMENTS } & \text { WAIVER } & \text { AAPM } & \text { IOMP } & \text { COMP/OCPM } & \text { ADVERTISING }\end{array}$

SPRING CLINICAL MEETING HOME LINKS ASSOCIATED ORGANIZATIONS

SUBMISSION GUIDELINES

Home > User > Author > Active Submissions

Active Submissions

ACTIVE ARCHIVE

\begin{tabular}{|c|c|c|c|c|}
\hline$\underline{\text { ID }}$ & $\begin{array}{l}\text { MM-DD } \\
\underline{\underline{\text { SUBMIT }} \text { SEC }}\end{array}$ & AUTHORS & IITLE & STATUS \\
\hline 6417 & 04-06 & $\begin{array}{l}\text { Nascimento, } \\
\text { Rodrigues }\end{array}$ & $\begin{array}{l}\text { PRESENTING THE SHIELDINGPET } \\
\text { APPUCATION TO BE USED IN... }\end{array}$ & IN REVIEW \\
\hline
\end{tabular}

1 - 1 of 1 Items

\section{Start a New Submission}

CLCK HERE to go to step one of the five-step submission process.

ISSN: 15269914 


\title{
Presenting the ShieldingPet application to be used in Nuclear
}

\section{Medicine: calculating the PET/CT shielding.}

\begin{abstract}
In this paper, we present an application (APP) that calculates the thicknesses of the barriers used in the shielding of positron emission in PET / CT facilites. The software was designed using the MIT Inventor2 App web tool for the Android platform. In order to demonstrate its application, this software was used to redo the examples suggested in the AAPM Task Group 108: PET report and the PET / CT Shielding Requirements of the American Association of Physicists in Medicine. The variations found betwen the results proposed by Task Group 108 and the ShieldingPet are small then 1,9\%, so the Application provides the user an instantaneous and more precise calculation of the thickness of the protection barrier.
\end{abstract}

Keywords: PET / CT shielding, medical physics, application, software.

\section{INTRODUCTION}

The PET/CT (Positron Emission Tomography/Computed Tomography) technique is the procedure through which images of human physiology are obtained by means of the identification of radio tracers of the metabolic activity injected into the patient [1]. As the name suggests, PET/CT is the combination of two types of exams, which allows us to simultaneously visualize functional and anatomic information of the body, therefore making the diagnosis more precise [2].

In the following picture we can see the results of each method used to obtain images and the two combined. 


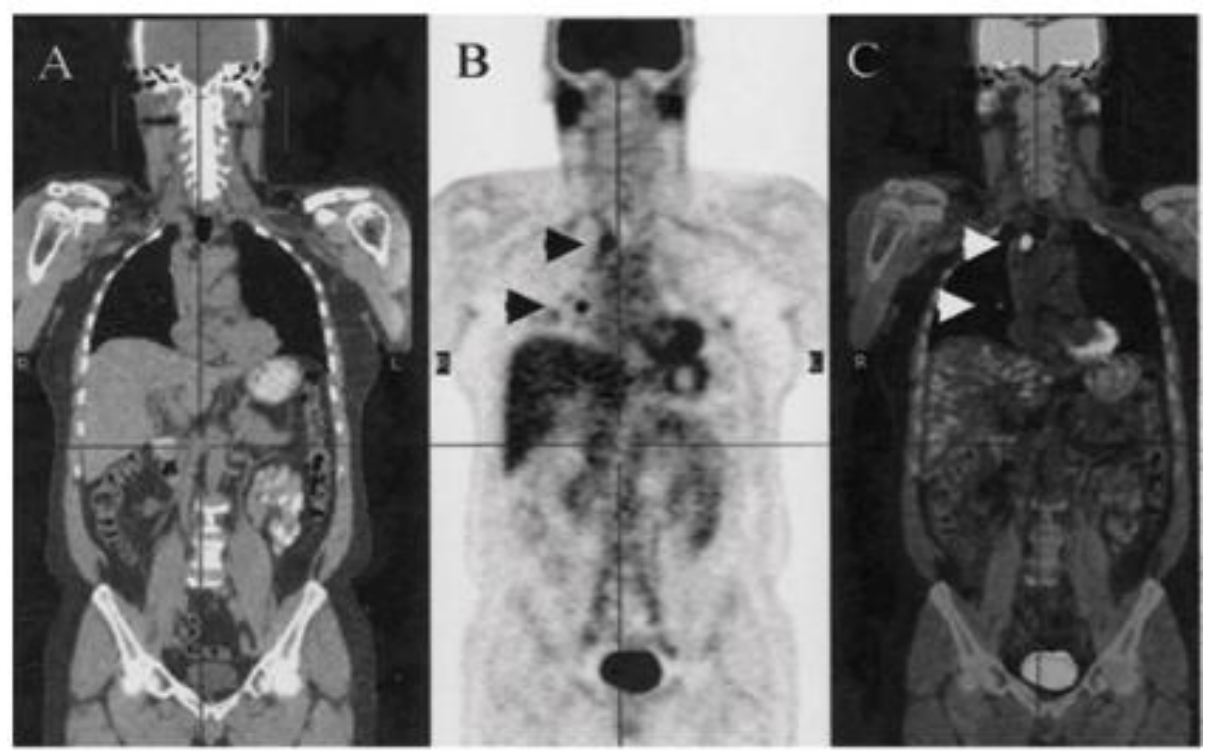

Picture $1-\mathrm{CT}$ coronal plane (A), FDG PET imaging $-{ }^{18} \mathrm{~F}(\mathrm{~B})$ and PET/CT imaging (C). The arrows in (B) and (C) indicate metabolic alterations that were diagnosed as cancer tumors. Source:[3].

Compounds (or molecules) marked by radionuclides, the radiopharmaceutical, follow specific functional or metabolic pathways inside the patients. Thus, the external detection of the radiation emitted by the radiopharmaceutical allows us to have an early diagnosis of many diseases, while anatomic alterations very often do not appear until relatively advanced stages, such as in the case of several types of cancer [4].

Within the several radiopharmaceuticals available, the ${ }^{18} \mathrm{~F}-$ fluorodesoxiglucose $\left({ }^{18} \mathrm{~F}\right.$ - FDG) is among the most used ones for this purpose because it accumulates in high concentrations in metabolically active tumors, as well as in the brain and the myocardium [5,6]. Having a 110 minutes half-life, $\beta+$ particles emitted by ${ }^{18} \mathrm{~F}$ after the annihilation give rise to two gamma rays with $511 \mathrm{keV}$ energy and, for that reason, they are appropriate for the diagnosis of metabolism and tumor imaging [7,8]. Due to the high photon energy, $511 \mathrm{keV}$, this technique demands specific procedures to calculate the shielding barrier with the purpose of radiological protection [9].

The difference between a PET/CT facility and a regular CT is that the patient becomes a radioactive source after he receives the radiopharmaceutical, which implies an additional concern that demands protection barriers to minimize radiation during the patient's stay in the facility.

According to federal code of regulations 10 CFR20 in USA or Brazilian's CNEN (Comissão Nacional de Energia Nuclear - National Nuclear Energy Commission), the radiation dose absorbed by an individual is measured in the international system in joule per kilogram $(\mathrm{J} / \mathrm{kg})$ and it is called sievert $(\mathrm{Sv})$. The annual dose 
limit cannot surpass $1 \mathrm{mSv}$ for public individuals or $20 \mathrm{mSv}$ for professionally exposed individuals [10]. The radiation dose injected into the patient is not enough to be harmful either to him or to the people living with him. However, the health team that carries out these exams - because it is composed of occupationally exposed individuals - needs protection since the radiation sum deriving from different patients during several days can be harmful. For that reason, shielding in the laboratories is so important. Protection barriers also help to protect the general public that needs to walk by near the facilities. After all, nobody should receive unneeded radiation doses that surpass the limit recommended.

The App was designed for the Android platform because it is widely used, it can be shared through Google Play Store and it does not demand a developer's license [11]. The programming was developed using the MIT App Inventor2 web tool.

ShieldingPet is still going through the registration process. Readers who are interested in the application can contact the authors through the email pedroan88@gmail.com.

\section{METHODS}

\section{SHIELDING CALCULATION}

In order to estimate the thickness of the protection barrier (x), the AAPM TG -108 report published by the American Association of Physicists in Medicine became a guide to calculate the PET/CT shielding [12]. The shielding estimate is calculated by means of the following mathematical relations:

$$
\begin{gathered}
\mathrm{x}=(1 / \alpha \gamma) \ln \left\{\left[\mathrm{B}^{-\gamma}+(\beta / \alpha)\right] /[1+(\beta / \alpha)]\right\} \\
\mathrm{B}=\frac{12,8 \cdot \mathrm{P} \cdot \mathrm{d}^{2}}{\mathrm{~T} \cdot \mathrm{N}_{\mathrm{w}} \cdot \mathrm{A}_{0} \cdot \mathrm{F}_{\mathrm{U}} \cdot \mathrm{t}_{\mathrm{I}} \cdot \mathrm{R}_{\mathrm{tI}}}
\end{gathered}
$$

In which $\alpha, \gamma$ and $\beta$ are specific parameters that vary according to the material used in the barrier and the amount of radiation expected and "B": a magnitude called transmission factor. When calculating the transmission factor, we insert the other magnitudes that influence the thickness shielding, such as: radiation weekly dose limit $(\mathrm{P})$, distance from source to barrier (d), occupancy factor $(\mathrm{T})$, number of patients per week $(\mathrm{Nw})$, administered initial activity (Ao), uptake time decay factor $(\mathrm{Fu})$, time in the imaging room (tI) and dose reduction factor in the imaging room (Rti). 
THE APP

In ShieldingPet, we have unified all the steps of shielding calculation and replaced the approximation tables for the effective shielding calculation. The user must insert the following variables: number of weekly patients, initial dose for each patient, time in the uptake room, time in the imaging room, distance between uptake room and CT scanner, occupancy factor and the type of area. The APP calculates and provides us with the dose parameters, the transmission factors and the shielding thickness for concrete and lead, as shown below in picture 2 .

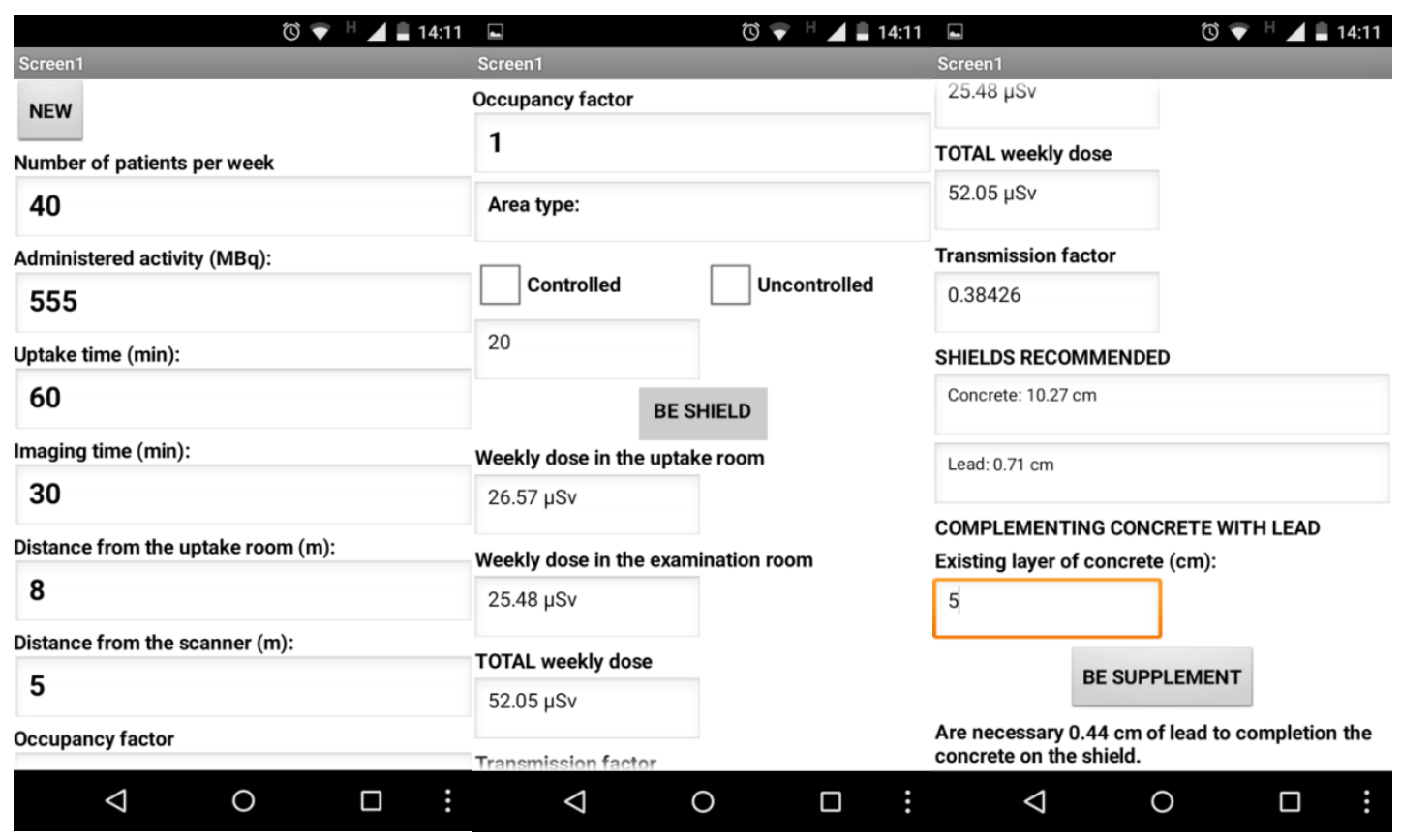

Picture 2 - Image of the ShieldindPet APP screen.

Another peculiarity of the APP is the possibility of calculating the thickness of the complementing lead barrier, which must be applied into a pre-existing concrete barrier. This is a recurring situation in the shielding calculation since concrete is widely used in Brazil to build the structural part of buildings.

\section{RESULTS}

In order to analyze the results presented by ShieldingPet, we have repeated the calculation of all examples proposed in the AAPM TG -108 report and there were no significant variations between the figures of transmission factor calculated by the APP and those calculated in the AAPM TG -108 report, as it is shown below in Table 1 . The variations we have found are inferior to $1,9 \%$. We have attributed these small differences 
to rounding issues related to decimal digits and precision, consequently all the thickness calculated by the APP are in accordance with the AAPM estimate.

Table 1 - Comparison between transmission factors and shielding suggested in the AAPM report and those calculated with ShieldingPet.

\begin{tabular}{|c|c|c|}
\hline & \multicolumn{2}{|c|}{ Transmission Factor } \\
\hline Room & AAPM & ShieldingPet \\
\hline Office 1 & 0,206 & 0,206 \\
\hline Office 2 & 0,169 & 0,169 \\
\hline Office 3 & 0,5 & 0,505 \\
\hline Office 4 & 0,629 & 0,637 \\
\hline Office 5 & 0,685 & 0,695 \\
\hline Office 6 & 0,872 & 0,885 \\
\hline Office 8 & 0,442 & 0,448 \\
\hline Office 9 & 0,685 & 0,693 \\
\hline PET control room & 0,817 & 0,814 \\
\hline Gamma Camera & 0,503 & 0,512 \\
\hline
\end{tabular}

\section{CONCLUSION}

Taking into account the expected PET/CET imaging growth, the appropriated design for imaging centers will continue to be one of the most significant challenges in radiation protection faced by physicists in medicine throughout the world [13]. Having this scenario in mind, we believe that our work can contribute to shielding calculation due to the speed of calculations, its convenience and above all its precision, apart from also enabling adaptations in cases of structural modifications.

The data presented in table 1 show that ShieldingPet provides the user with an instantaneous and more precise calculation of the thickness of the protection barrier. For this reason, it is a useful tool for medical physics professionals that need to execute this type of calculation. Another envisioned application is to use the App in training courses and when teaching the shielding methodology to professionals and students in the area.

\section{REFERENCES}

[1] Peet D J, et al. Radiation protection in fixed PET/CT facilities—design and operation. Br J Radiol. 85. (May 2012).

[2] Basic of PET-CT. Look at: http://www.med.harvard.edu/JPNM/chetan/petct/petct.html, january 2016. 
[3] Yamaga, Lilian Yuri Itaya et al. Valor diagnóstico da tomografia por emissão de pósitrons / tomografia computadorizada (PET-CT) com flúor-18 fluordeoxiglicose (FDG-18F) em pacientes com carcinoma diferenciado da tireoide, níveis séricos de tireoglobulina elevados e pesquisa de corpo inteiro com iodo negativa. Arquivos Brasileiros de Endocrinologia \& Metabologia. Vol 51. No 4. São Paulo. (June 2007).

[4] Robilotta CC. A tomografia por emissão de pósitrons: uma nova modalidade na medicina nuclear brasileira. Revista Panamericana de Salud Pública. (2006).

[5] Krabbe CA, Balink H, Roodenburg JL, Dol J, de Visscher JG. Performance of 18F-FDG PET/contrastenhanced CT in the staging of squamous cell carcinoma of the oral cavity and oropharynx. International Journal of Oral and Maxillofacial Surgery. (2011).

[6] Nestle U, Kremp S, Grosu A-L. Practical integration of [18F]-FDG-PET and PET-CT in the planning of radiotherapy for non-small cell lung cancer (NSCLC): the technical basis, ICRU-target volumes, problems, perspectives. Radiotherapy Oncology. 81. (2006).

[7] Henríquez Francisco Cutanda, Castrillón Silvia Vargas. Impact of a PET/CT Facility in its Community Environment. Revista Española de Salud Pública. Vol 85. N³. Madrid. Maio/ Junho (2011).

[8] Antic Vojislav et al. Comparison of various methods for designing the shielding from ionising radiation at pet-ct installations. Radiation Protection Dosimetry. Vol 154. № 2. (2013).

[9] Correia Paula D, Granzotti Cristiano R F, Santos Yago S, Brochi1 Marco A C, Marques Paulo M Azevedo. Caracterização de uma blindagem de chumbo protetora de mamas para redução de dose em exames de Tomografia Computadorizada. XVIII Congresso Brasileiro de Física Médica. (Agosto 2013).

[10] CNEN. Diretrizes Básicas de Proteção Radiológica . CNEN NN-3.01:2011 (Setembro/2011).

[11] MIT App Inventor, Explore MIT App Inventor, 2015. Look at: http://appinventor.mit.edu/explore, january 2016.

[12] Madsen M T et al, AAPM Task Group 108: PET and PET/CT Shielding Requirements. Medical Physics. Vol 33. № 1. (Janeiro 2006).

[13] Pasciaka Alexander S, Jones A Kyle. PShield: An exact three-dimensional numerical solution for determining optimal shielding designs for PET/CT facilities. Medical Physics. Vol 39. $\mathrm{N}^{\circ}$ 6. (Junho 2012). 
Anexo 4 - Normas para publicação ARTIGO 2.

\section{SUBMISSION PREPARATION CHECKLIST}

As part of the submission process, authors are required to check off their submission's compliance with all of the following items, and submissions may be returned to authors that do not adhere to these guidelines.

1. The submission has not been previously published nor is it before another journal for consideration; or an explanation has been provided in Comments to the Editor.

2. The submission file is in Microsoft Word (.doc file, not .docx) or RTF document file format and uses Times New Roman font or equivalent.

3. All URL addresses in the text (e.g., http://pkp.ubc.ca) are activated and ready to click.

4. The text is double-spaced; uses a 10-point font; employs italics, rather than underlining (except with URL addresses); with figures and tables placed at the end of the text, rather than within.

5. The text meets this journal's formatting requirements outlined in the Author Guidelines found on the front page of the JACMP web site. If the journal section is peer reviewed, author identification has been removed, and ";Author"; and year have been used in the bibliography and footnotes, instead of authors' names, titles, etc. The author's name has been removed from the document's Properties, which in Microsoft Word 97 - 2003 is found in the File menu. In Word, the instructions are File>Save as $>$ Tools >Save Options $>$ Trust Center Settings... >Privacy Options > select "Remove personal information from file properties on save" > OK

6. I have provided figures to be uploaded as Supplementary Files in JPG, GIF or PNG with 100 - 150 pixels per inch (color) or 100 - 150 dpi (grayscale). Monochrome images have been saved in grayscale mode; color images are in RGB. I have included no BMP, RTF or TIF images. Images are at least 3 inches and no greater than 5 inches in the greatest dimension.

7. I have imbedded figures within the submission file, which is in word or RTF format. These figures are placed at the end of the document immediately after the References and before the tables. Figure legends are included below the 
figures. Figures have the same resolution as the gif or jpg files which are uploaded separately as supplementary files. I have placed the tables after the figures and included table captions. I understand the figures are required within the submission file for review purposes, and also as separate files for layout editing.

8. IMPORTANT - Perform a Google Scholar search (http://scholar.google.com/) on the keywords of your article as well as key terms from your title and abstract followed by "JACMP". This should locate all JACMP articles that should be cited by your article in order to maintain the continuity of the investigational narrative within the JACMP community. Please be sure to cite all relevant JACMP articles for your submission.

9. The submission has not been previously published nor is it before another journal for consideration; nor will it be until after such time as the manuscript has either been withdrawn from further consideration or it has been decided that the manuscript will not be published in Journal of Applied Clinical Medical Physics or an explanation has been provided to the Editor and written permission obtained.

10. It is understood that an Article Processing Charge (APC) is payable for articles accepted for publication in the Journal of Applied Clinical Medical Physics. The APC is $\$ 500.00$ USD. The APC applies for all articles submitted after midnight, November 1, 2015, US Pacific Time. For more information, please visit our page "About Author Fees". 
Anexo 5 - Pedido de Registro - Blindpet

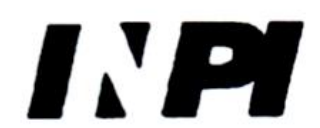

PEDIDO DE REGISTRO DE PROGRAMA DE COMPUTADOR

IDENTIFICAÇAO DO PEDIDO (Para uso do INPI)

Número do Pedido
$\Gamma$

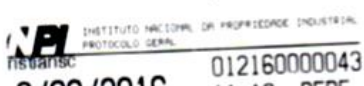

$2 / 02 / 2016 \quad 11: 18$ DEDF

BR 5120160001275

L

Protocolo, Data e Hora

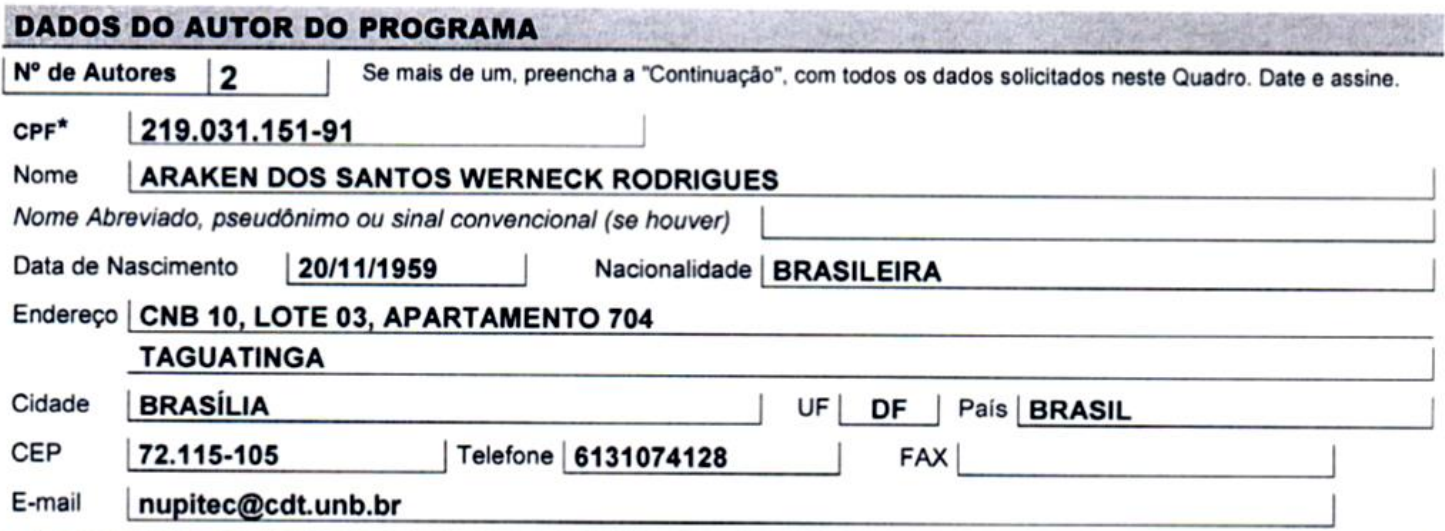

\section{DADOS DO TITULAR DOS DIREITOS PATRIMONIAIS}

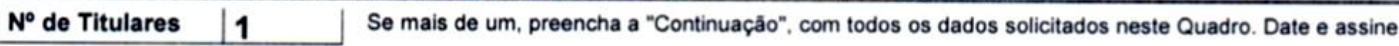
CPF/CNPJ* 00038174000143

Nome/Razão Social FUNDAÇÃO UNIVERSIDADE DE BRASÍLIA

Nome abreviado, pseudonimo ou sinal convencional (se houver) IFUB

Data de Nascimento Nacionalidade/Origem

Endereço UNIVERSIDADE DE BRASÍLIA, ED. CDT CAMPUS UNIVERSITÁRIO DARCY RIBEIRO

\section{ASA NORTE}

Cidade |BRASILIA

CEP $\quad$ 70.904-970 UF DF Pais LRASIL

E-mail nupitec@cdt.unb.br

Q SIM. este Titular \& Pessoa Juridica. Caso afirmativo, assinale a melhor classificacăo:

$\bigotimes$ Instituiçăo Pública de Ensino ou Pesquisa $\quad \square$ Instituiçăo Privada de Ensino ou Pesquisa

Software House

$\square$ Outras

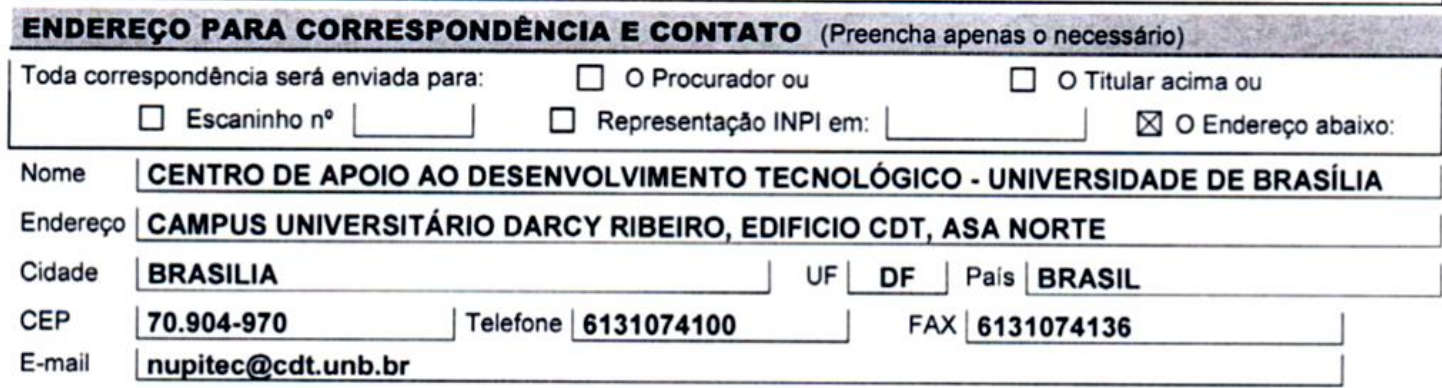


Anexo 6- Pedido de Registro - Dosepet

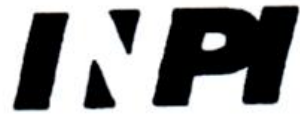

PEDIDO DE REGISTRO DE PROGRAMA DE COMPUTADOR
$\Gamma$

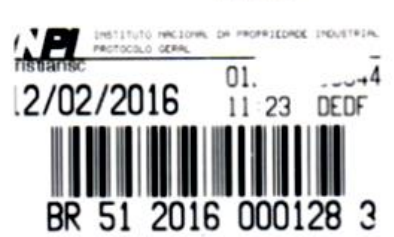

IDENTIFICACAO DO PEDIDO (Para uso do INPI)

Número do Pedido

Protocolo, Data e Hora

\section{DADOS DO AUTOR DO PROGRAMA}

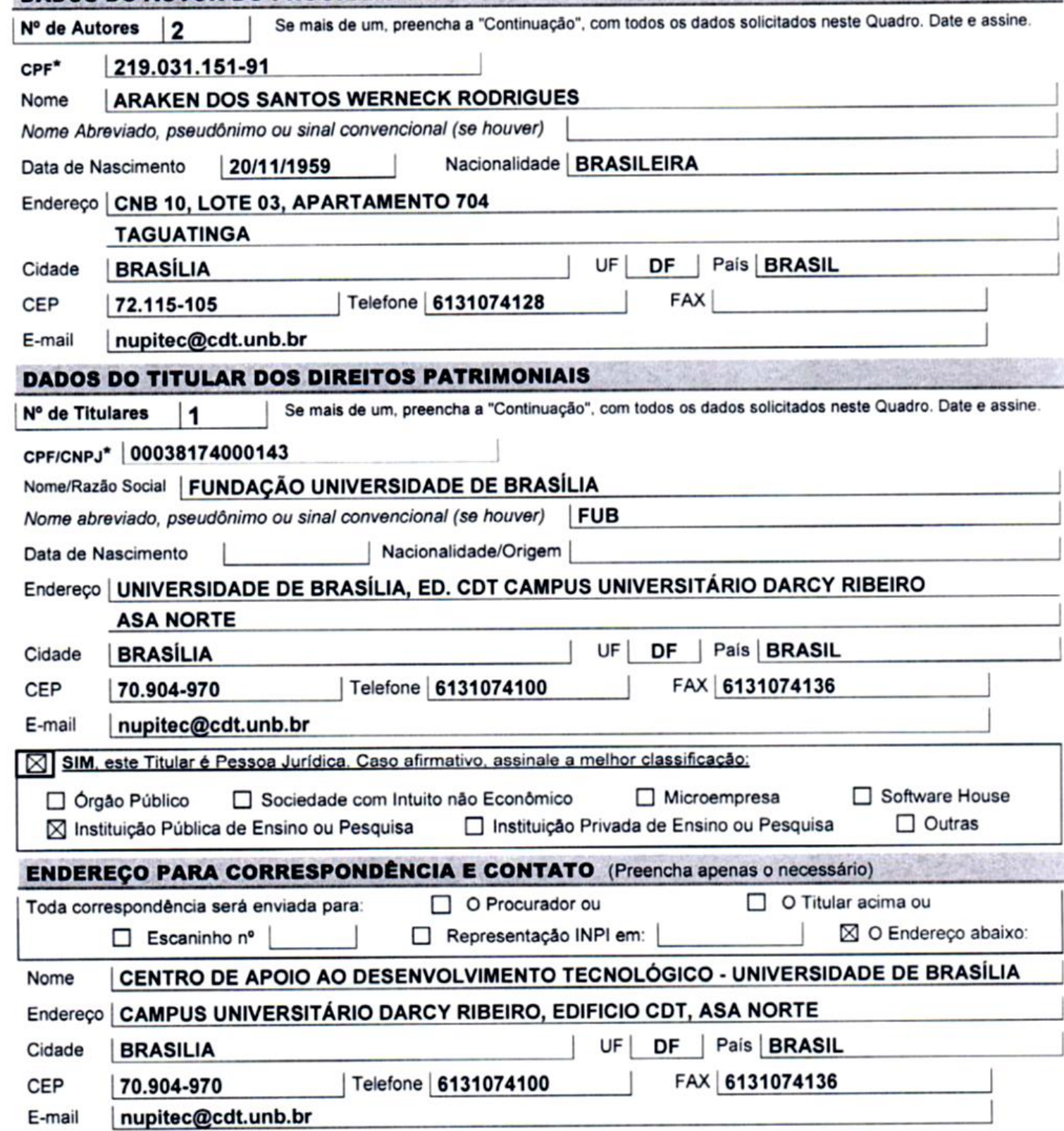

